\title{
Proyecto arquitectónico basado en la técnica del antifunicular
}

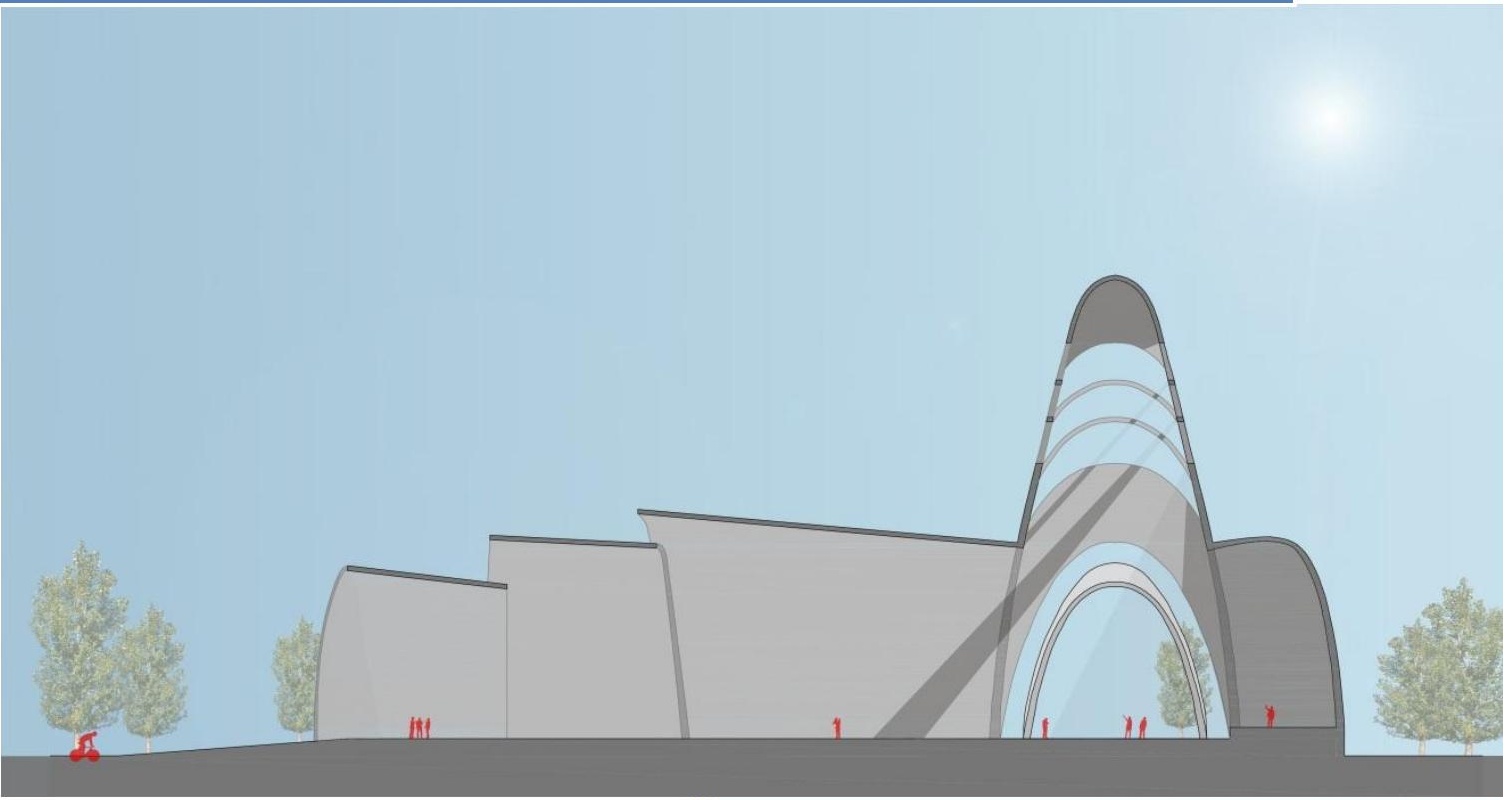

Laura Butelo Naz

Tutor/Director: Luisa María Gil Martín

Codirector: Juan Francisco Carbonell Márquez 
"La Obra mejor es la que se sostiene por su forma" Eduardo Torroja 


\section{CONTENIDO}

Resumen 3

1 Objetivos $\quad 4$

2 Introducción

2.1 Contextualización 5

2.2 El material $\quad 6$

2.3 La obra

2.4 El arco catenario

2.4.1 Antecedentes 9

2.4.2 Arco catenario 10

2.4.3 Propiedades del arco catenario. Fundamentos matemáticos $\quad 14$

3 El proyecto arquitectónico $\quad 17$

$\begin{array}{ll}3.1 \text { Diseño } & 17\end{array}$

4 Desarrollo $\quad 20$

4.1 Objetivos $\quad 20$

4.2 Instrumentación y preparación $\quad 20$

4.3 Toma de muestras $\quad 21$

4.4 Cálculo de fuerzas $\quad 21$

4.5 Resultados 28

5 Propuesta de aplicación $\quad 31$

6 Conclusiones $\quad 32$

7 Anexos $\quad 33$

7.1 Planos de proyecto 33

$\begin{array}{ll}\text { Referencias } & 34\end{array}$ 


\section{RESUMEN}

La arquitectura actual busca nuevas formas de reinvención y simplificación, además de convertirse en hitos o iconos en urbes contemporáneas. El arco catenario distribuye los esfuerzos a lo largo de la curva que forma, transmitiéndolos a los apoyos directamente, sin tensiones adicionales más que los esfuerzos producidos por el propio peso del material que lo conforma. Construcciones basadas en esta forma geométrica, han venido realizándose desde tiempos remotos, manteniéndose muchas de ellas aún en pie. Es por ello, por lo que se propone realizar un proyecto arquitectónico basado en esta técnica, hallando los esfuerzos resultantes a lo largo de la estructura hasta sus apoyos y demostrando la simplicidad del método. Un método que puede rebajar costes en el proceso tanto constructivo como proyectual de manera considerable. 


\section{OBJETIVOS}

La finalidad del presente trabajo consiste en el desarrollo de una maqueta de catenarias para obtener sus antifuniculares. Esta maqueta dará lugar a la forma óptima de la estructura del proyecto, de modo que sólo existan trabajos a compresión, aproximándose al trabajo de Gaudí como medio para realizar los cálculos estructurales de sus obras.

Una vez realizada la maqueta, se digitalizarán las curvas obtenidas y se hallarán sus longitudes y demás parámetros necesarios para obtener las fuerzas resultantes. Un predimensionado alternativo y bastante aproximado al resultado real que da lugar a una estructura de menor coste y trabajo.

De manera previa a este proceso se ha justificado la idea del proyecto base y los materiales que idóneos para su posible construcción. El material elegido sirve como referente a la hora de calcular los esfuerzos en las estructuras halladas. 


\section{INTRODUCCIÓN}

\subsection{Contextualización}

El mundo contemporáneo en el que vivimos se basa en la cultura de la globalización; una sociedad de consumo en muchos aspectos. En lo que refiere a la arquitectura, ha venido desarrollándose bajo el afán de "ver y ser visto", ver en el sentido de posicionarse lo mas alto posible, para destacar entre las masas, y ser visto como forma de convertirse en símbolo, en un icono dentro de ciudades conglomeradas. Aunque esto ha venido realizándose desde tiempos remotos, la cualidad de la arquitectura actual es su fecha de caducidad temprana.

Grandes ciudades como Sevilla, Córdoba o Granada son ricas en patrimonio, pero ¿qué es patrimonio? El patrimonio arquitectónico es la ciudad heredada, son los vestigios del tiempo, pero que aún prevalecen. Aquello que levantaron nuestros antepasados y que aún siguen en pie. Su prevalencia recae sobre la cualidad de sus materiales y formas de construcción, además del mantenimiento y la suerte que pueda tener el edificio ante sucesos inesperados.

En cuanto a los materiales, tan sólo tenemos que echar un vistazo a los edificios más antiguos de nuestra ciudad; la mayor parte de ellos están erigidos mediante materiales pétreos, sobre todo la piedra en sí. Bloques de piedra que levantan catedrales o importantes edificios, dando vida a impresionantes arquerías y cúpulas, o a fachadas que parecen estar vivas.

La piedra es un material de gran resistencia a compresión y de gran durabilidad. Con una densidad de 2.300 a $2.500 \mathrm{Kg} / \mathrm{m}^{3}$, la resistencia a compresión de la piedra en edificios oscila entre los 60 y los $200 \mathrm{~N} / \mathrm{m}^{2}$, su porosidad dependerá del tipo de piedra, con unos porcentajes de entre el $1 \%$, en piedras tipo granito o pizarra, a un $10 \%$, en areniscas o calizas (\% de absorción de agua por volumen a 24 horas sumergida). Otras propiedades características de los materiales pétreos es la alta resistencia a la erosión en el tiempo y su resistencia al fuego, de más de $500^{\circ} \mathrm{C}$.

Todo ello ha hecho que edificios como la Mezquita de Córdoba o la Catedral de Sevilla sigan prácticamente intactos tras varios siglos de antigüedad. Sin embargo, como mencionábamos antes, desde unos años atrás, la arquitectura que se viene haciendo está siendo desarrollada mediante hormigón armado. Este material permite desarrollar formas inimaginables debido a su gran plasticidad, y su resistencia es aportada por elementos de acero, haciendo que, además de resistir a compresión, resista esfuerzos de tracción y flexión. El hormigón en sí, está compuesto por materiales pétreos, por lo que, una vez endurecido, resistirá por sí solo a compresión. 


\subsection{El material}

El hormigón es una mezcla de agua, cemento y áridos como componentes principales. Además, pueden añadírsele aditivos ( $<5 \%$ del peso de cemento) para mejorar algunas cualidades, o adiciones. El uso de estas sustancias, además de mejorar propiedades concretas, como la trabajabilidad temporal del propio hormigón o su color, sirven para abaratar el coste de la mezcla.

La función del agua en la mezcla es la de reaccionar químicamente con el cemento, produciendo una pasta moldeable. Tras poco tiempo la mezcla se endurece, habiendo adoptado la forma del molde que se le haya impuesto y dando una apariencia pétrea. El agua en exceso, al evaporarse, dejará poros en el interior de la estructura, haciendo del hormigón un elemento más o menos poroso, en función de la cantidad de agua añadida, y, por tanto, tendrá una menor o mayor resistencia a compresión. La resistencia del hormigón, al cabo del tiempo, aumenta en el orden de un $10 \%$ con respecto a la resistencia adquirida a los 28 días, que es el tiempo de curado.

En cuanto a las propiedades mecánicas del hormigón, como hemos mencionado, la principal es la resistencia a compresión $\left(f_{c}\right)$, que es la obtenida a partir del ensayo de rotura en probeta cilíndrica. La normativa correspondiente que especifica los requisitos mínimos para el empleo de este material es la EHE, de carácter nacional, y el Eurocódigo, a nivel europeo.

El empleo de este material es básicamente para vigas, láminas, etc., dónde existen zonas que solicitan esfuerzos a tracción. La resistencia del hormigón por sí sólo ante este esfuerzo es baja, por lo que se emplean barras de acero de distintos diámetros, en función de las cargas a soportar por el conjunto hormigón-acero. La principal desventaja del empleo de acero es su corrosión, por lo que las normativas especifican recubrimientos mínimos para protegerlas ante los agentes meteorológicos, que son los responsables de su deterioro. Ante esta situación, aparece el término durabilidad, que es la capacidad para resistir la acción de la meteorización, los agentes químicos, la abrasión o cualquier otro proceso de deterioro. Un hormigón durable conservará su forma, calidad y serviciabilidad originales al estar expuesto a un ambiente. Al cabo del tiempo, la armadura, de un modo u otro, se verá afectada. Cuando ésta se corroe, aumenta su volumen, afectando al hormigón que la rodea produciendo tensiones que acabarán por romperlo y produciendo reacciones químicas que lo deteriorarán. 

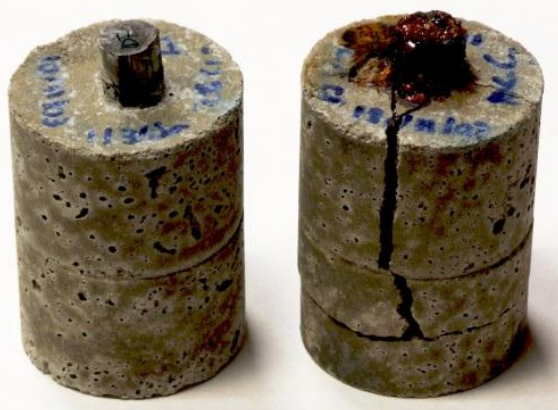

Fig. 1. Probetas de hormigón armado y acción de la corrosión.

Fuente: UC3M

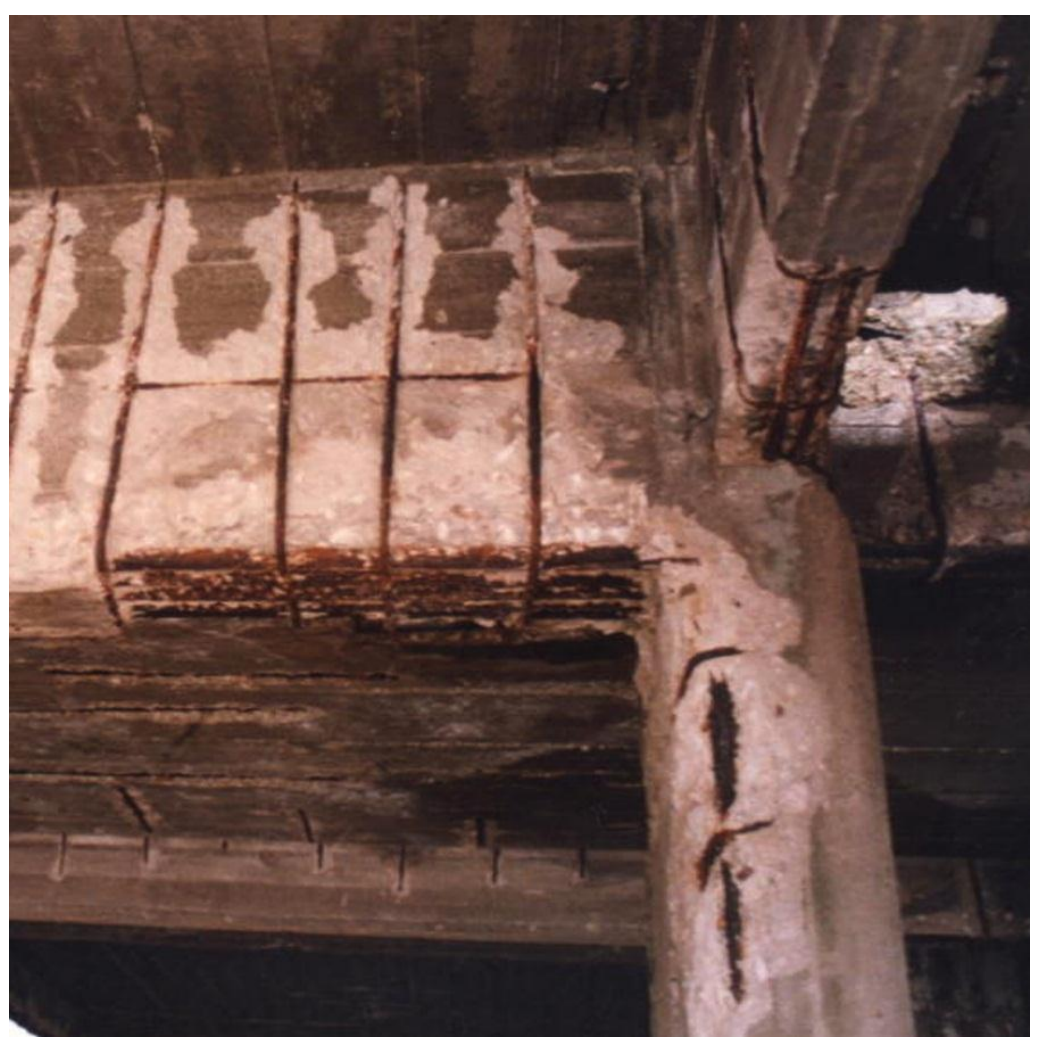

Fig. 2. Hormigón armado deteriorado Fuente: Montenegro Gambini, J.

Otra propiedad del hormigón, de carácter básico, es su densidad, que aproximadamente es de $2.300 \mathrm{Kg} / \mathrm{m}^{3}$ para hormigón en masa y de $2.500 \mathrm{Kg} / \mathrm{m}^{3}$ para hormigón armado. 
Por tanto, si hablamos en términos de permanencia en el tiempo, el uso de armaduras no es lo más adecuado para nuestra estructura, pero sí lo es el hormigón. El hormigón como alternativa a la perdurable piedra. Su empleo nos permitirá crear bloques a medida, mediante encofrados diseñados para tal fin, y para su completa aceptación en el proyecto, deberá trabajar puramente a compresión.

\subsection{La Obra}

Como se menciona al principio de este apartado, sentimos la necesidad de crear patrimonio, de crear algo que resista el paso del tiempo. Aunque llegará el momento en el que nos tengamos que rendir a su paso...

Un espacio público que sirva de templo puede ser un gran modo de dejar una pequeña huella en medio de una caduca urbe. Una catedral es un símbolo importante de prevalencia y es por ello por lo que la tomaremos como elemento arquitectónico con el que desarrollar este trabajo de investigación.

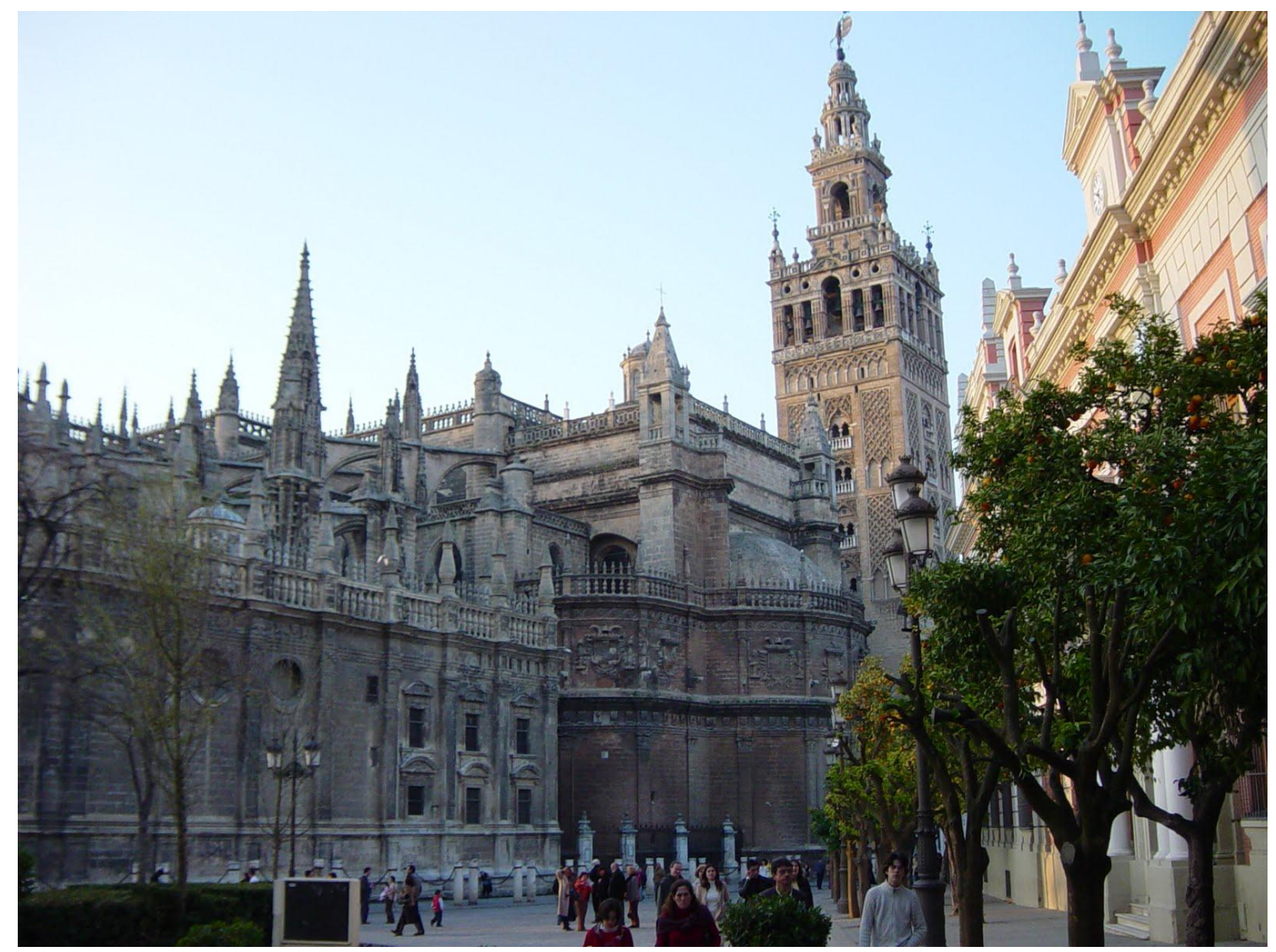

Fig. 3: Catedral de Sevilla 


\subsection{El Arco Catenario}

\subsubsection{Antecedentes}

La estática es una de las ciencias de la física que utiliza los métodos gráficos para determinar, de manera óptima, situaciones estructurales a construir. Su objetivo es resolver un equilibrio estable por medio de dibujos exactos $y$, ha venido utilizándose desde tiempos del mismo Leonardo Da Vinci (1452-1519), con su axioma del Paralelogramo de Fuerza.

Los primeros estudios sobre la forma que adoptaba una cuerda o cadena colgada por sus extremos intentaban buscar cuál era la curva que la describía. Hombres de la talla de Galileo erraron en su solución, puesto que asumió que tal curva era una parábola en sus Diálogos sobre dos nuevas ciencias, de 1638.

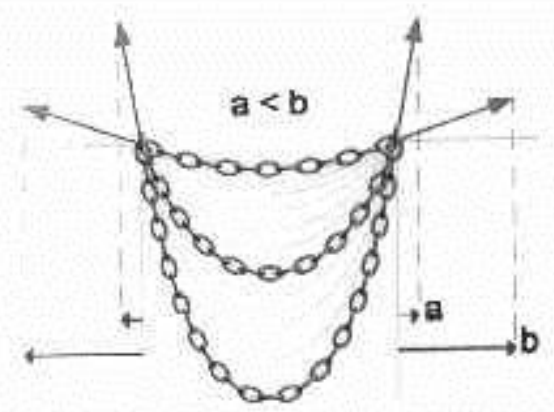

Fig.4: Forma catenaria

A día de hoy, sabemos que el trazado de la parábola se acerca bastante al de la catenaria, sin embargo, la parábola está descrita por una ecuación cuadrática y, la catenaria, incluye hasta términos elevados a la cuarta.

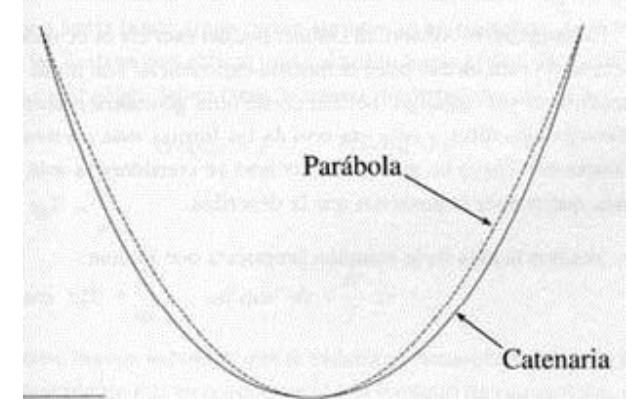

Fig.5: Catenaria Vs. Parábola 
No fue hasta 1691 cuando Johann Bernoulli, Gottfried Leibniz y Chistiaan Huygens hallaron la fórmula matemática que definiera la auténtica forma de una cadena colgante. Es entonces cuando se emplea por primera vez el término catenaria. Este término que deriva del latín catena, cuyo significado es cadena, se ha impuesto a otros sinónimos como curva funicular o chainette.

Estudios sucesores intentaban buscar la forma de colgar pesos en una cuerda para que adquiriera forma parabólica, problema resuelto por David Gregory en los primeros tratados de curvas, 1691, y más tarde, en 1744, Leonhard Euler demostró que la catenaria es la curva que, rotada sobre el eje $\mathrm{x}$, produce una forma tridimensional, el catenoide, que tras el plano fue la primera superficie mínima descubierta.

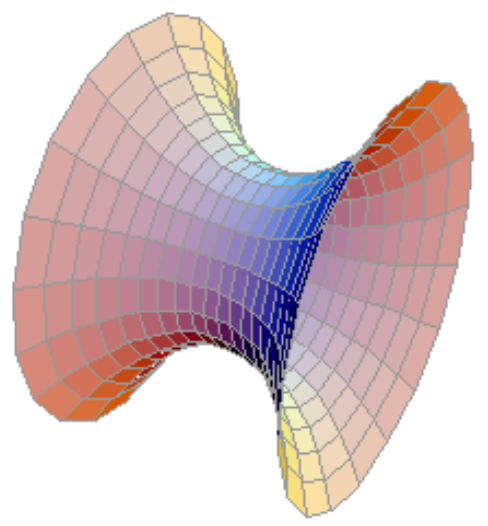

Fig.6: Catenoide. Fuente: www.xtec.cat

\subsubsection{Arco catenario}

Si a una cadena, colgada de sus dos extremos, le damos la vuelta obtenemos el arco catenario. Esta forma conserva todas las características de la curva catenaria y resulta ideal para el arco que debe soportarse a sí mismo. A la hora de construir un arco catenario, los elementos que lo componen deben ser perpendiculares a la curva del arco. De esta manera, no existirán fuerzas significativas de cizalla en las uniones y el empuje se transmite a lo largo de la línea del arco al apoyo. Se da, además, que para arcos catenarios con la misma longitud entre apoyos, cuánto mayor es la altura menor es el empuje horizontal en los puntos de arranque, pudiéndose obtener grandes alturas con mínimos empujes laterales. 


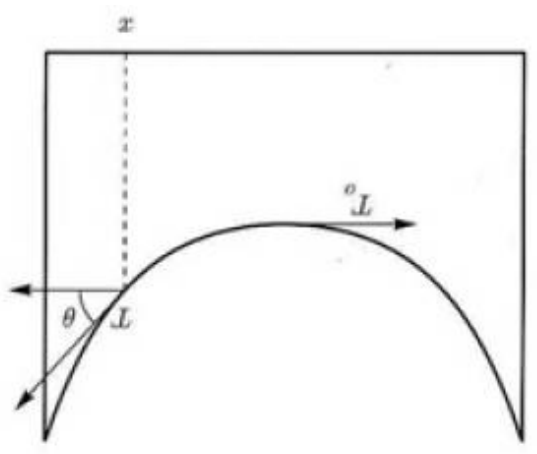

Fig.7. Catenaria invertida y arco catenario

Desde el antiguo oriente, se construyeron arcos estables intuitivamente, con la curvatura de catenarias invertidas. Sin embargo, en la cultura occidental, desde Grecia y Roma, se desarrollaron arcos menos eficientes con formas derivadas del círculo, de más sencilla ejecución, pero de estabilidad menor. Tan sólo fue el arco gótico la ejecución que más se aproxima a la curva ideal.

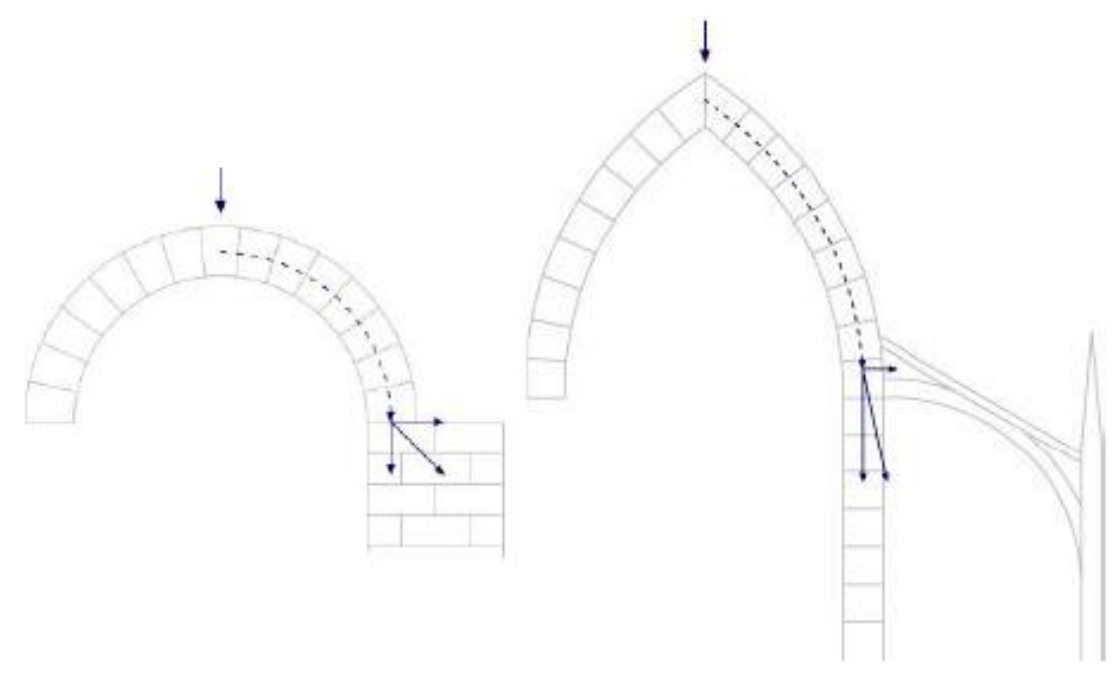

Fig. 8. Transmisión de fuerzas en arcos románicos y góticos

Existen, además, estudios geométricos que demuestran que los iglús de los esquimales canadienses no son semiesferas, sino que su morfología se aproxima más a catenoides de revolución, con una relación altura/diámetro óptima. 
En nuestro país, la mejor representación del arco catenario contemporáneo fue llevada a cabo por el arquitecto Antonio Gaudí (1852-1926). El modernismo catalán se vio muy influido por las formas que este arquitecto ideaba, siendo Barcelona su principal escenario. Desde obras como el Colegio de las Teresianas (1887-1889) a la Sagrada Familia (1882-), pasando por el parque Güell (1900-1914), el arco catenario le ha servido como forma estructural y, al ser un elemento natural, un referente continuo para sus formas.
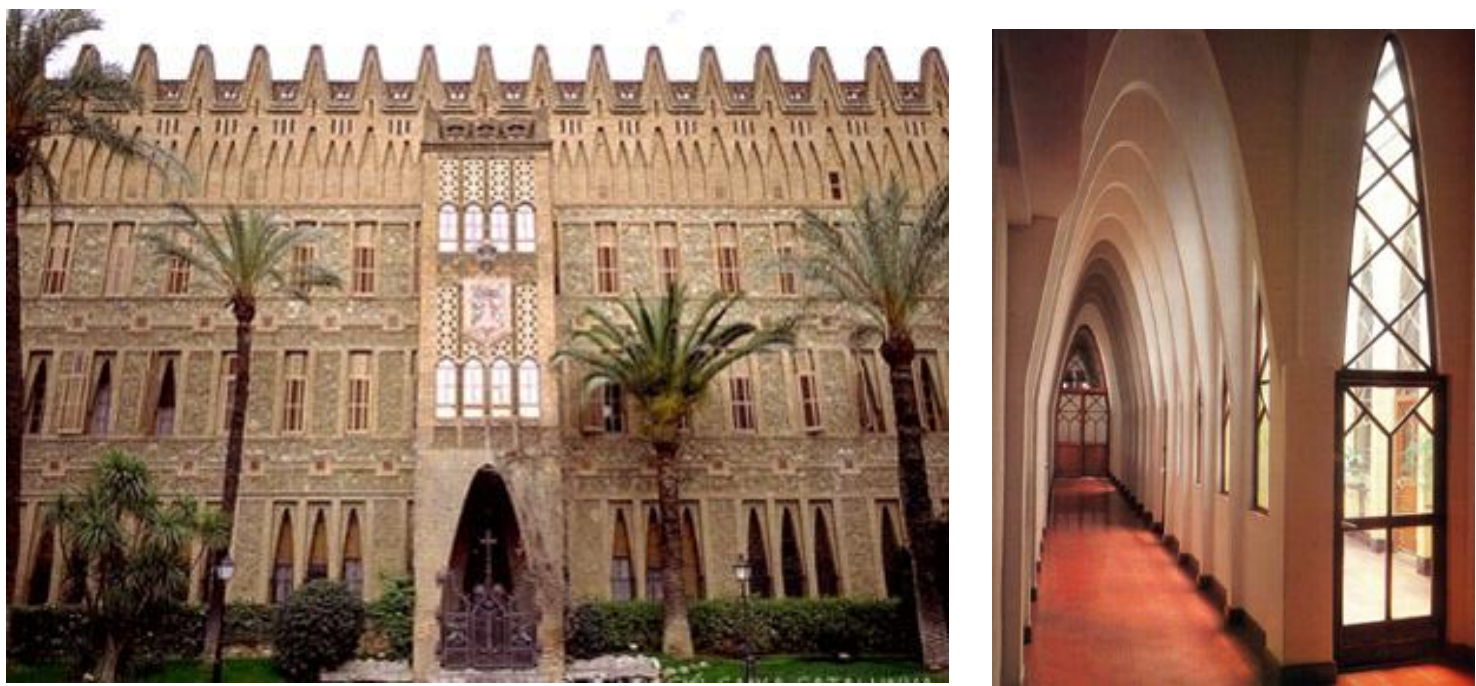

Fig. 9: Colegio de las Teresianas, Barcelona. Antonio Gaudí
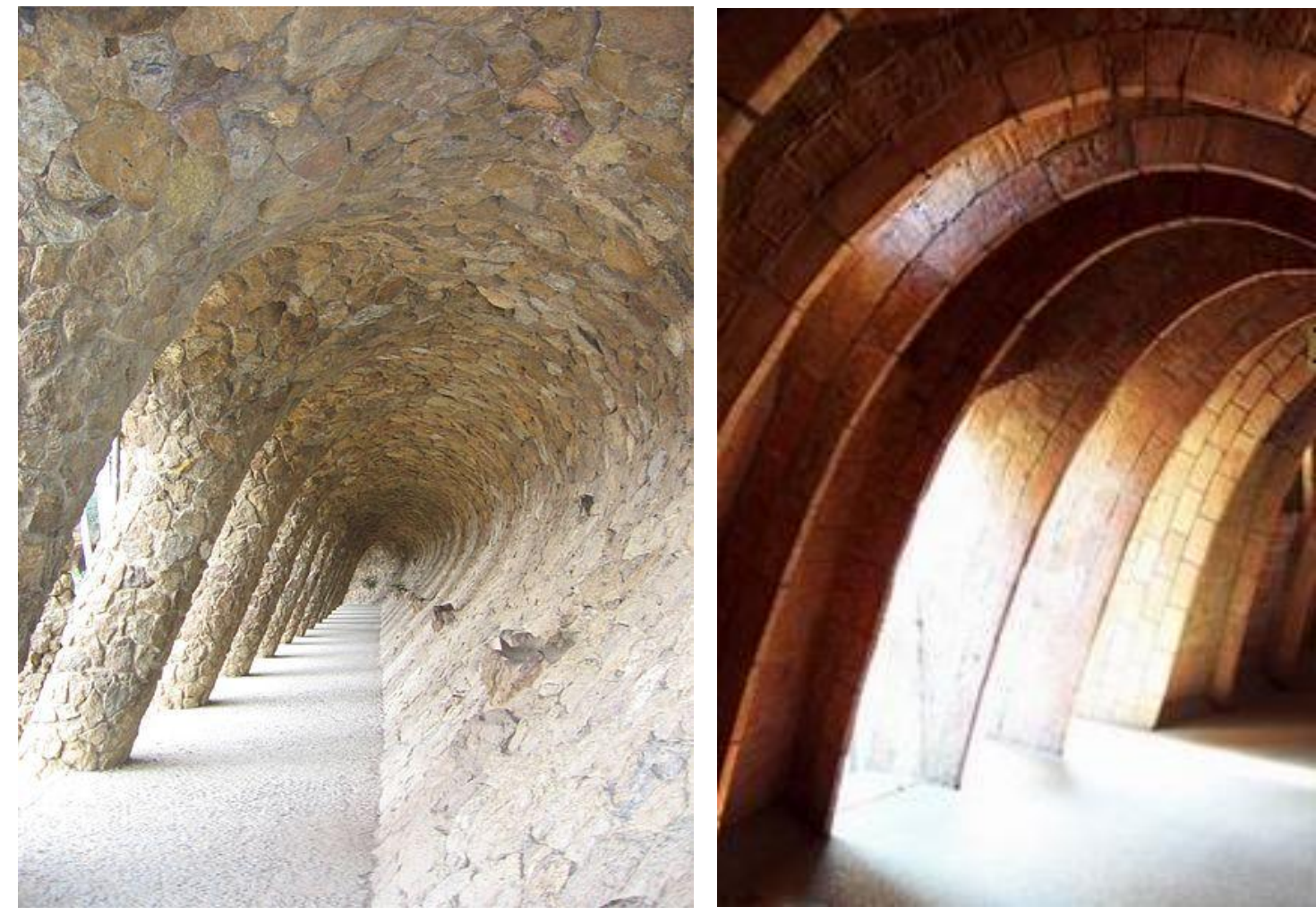

Fig. 10 y 11: Pórtico Parque Güell e interior de la Casa Batlló 
Gaudí llegó a afirmar que "...la catenaria da elegancia y espiritualidad al arco, elegancia y espiritualidad a la construcción entera", "evita contrafuertes, el edificio pesa menos, gana elegancia vaporosa y se aguanta sin raros accesorios ortopédicos".

Por otro lado, la ejecución del arco catenario resulta sencilla para los trabajadores, ya que sólo debían de disponer de una cadena colgada y, con la flecha deseada del arco, se dibujada la forma adoptada por la catenaria y el carpintero construía la cercha que posteriormente se invertía.

Gaudí utilizó este principio de inversión de cadenas colgantes para obtener el arco catenario, utilizándolo para realizar maquetas como la del proyecto para la iglesia de la colonia Güell, simulando arcos, columnas y pesos suspendidos para lograr formas deseadas. Otra maqueta basada en estos principios es la realizada para la Sagrada Familia, mediante hilos y pesos logrando antifuniculares. Estas maquetas, a escala, le permitieron predecir deformaciones y, así, hallar las formas más estables posibles.

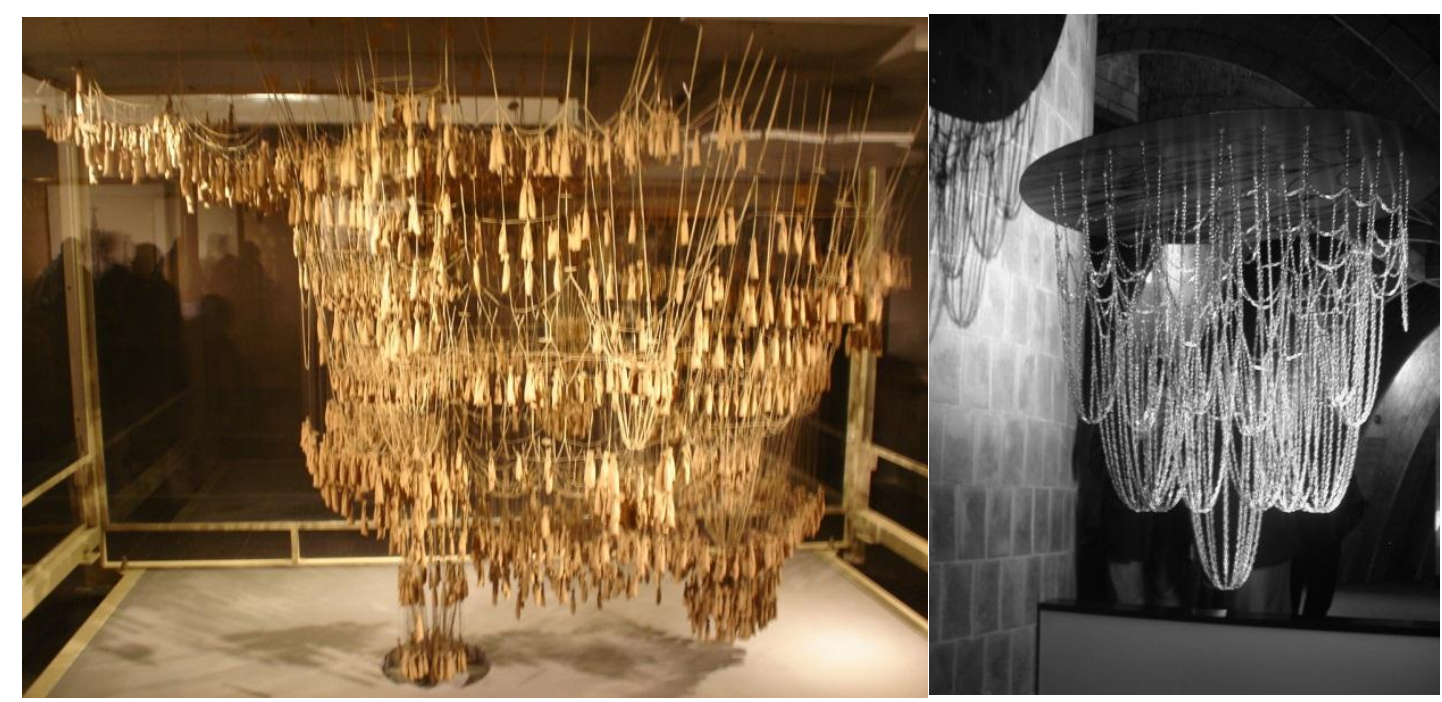

Fig. 12: Maqueta estereofunicular para la Sagrada Familia. En la Sagrada Familia, Barcelona Fig. 13: Maqueta de catenarias. En casa Milá, Barcelona

Algo más adentrados en el siglo XX, encontramos una gran obra arquitectónica con forma de arco catenario. De la mano del arquitecto finlandés Eero Saarinen, una obra ganadora de un concurso nacional de 1947, The Gateway Arch de San Luis (Missouri) fue creado para constituir un monumento en recuerdo de los pioneros de la conquista del Oeste americano, incluido junto con el Museo de la Conquista del Oeste y el antiguo edificio de los Juzgados de San Luis en el Thomas Jefferson National Memorial. 
Saarinen quiso dar vida a este monumento con la "forma perfecta". El arco es el monumento más alto de los Estados Unidos, con 192 metros, tanto de alto como de separación entre los puntos de arranque. La sección del arco es un triángulo equilátero cuya superficie disminuye a medida que asciende, con unos cimientos que se hunden casi 20 metros en el terreno. En su interior existe un sistema de ascensores que da acceso al observatorio, situado en la cúspide.

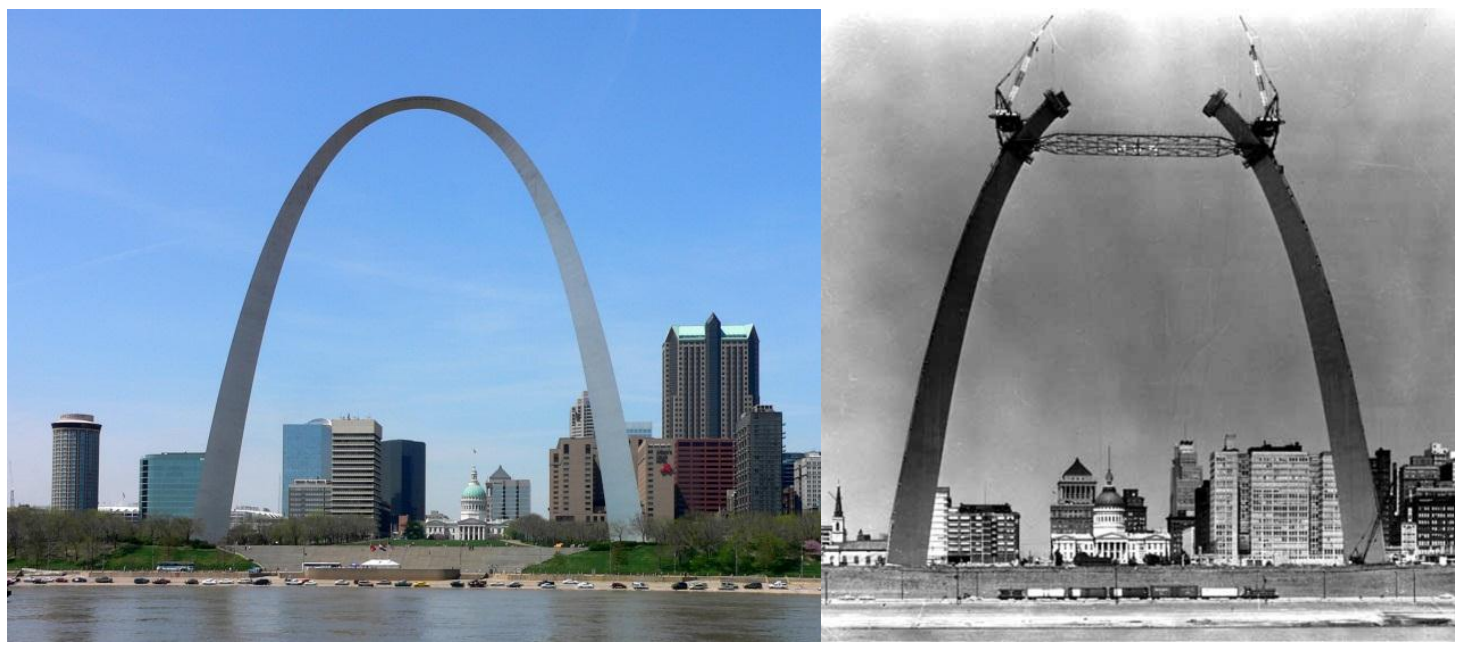

Fig. 14: The Gateway Arch, San Luis (Missouri). Eero Saarinen

Fig. 15: Proceso de construcción de The Gateway Arch.

\subsubsection{Propiedades del arco catenario}

"La construcción, la arquitectura, no pueden prescindir de la realidad del fenómeno físico, esto es, de las leyes de la estática. Su belleza se funda esencialmente sobre la verdad, sobre la racionalidad de la estructura; debe, por tanto, poderse lograr sin adiciones ni ornamentaciones externas. Pero, para obtenerla, es necesario un esfuerzo largo y tenaz en el sentido de las íntimas razones de resistencia de las formas. El resultado genial de un momento de inspiración es siempre el epílogo de un drama, que frecuentemente está constituido por toda una vida de trabajo." Eduardo Torroja.

Como se ha mencionado previamente, si se invierte el trazado de un funicular o catenaria, obtenemos un antifunicular o arco catenario de propiedades idénticas. Las fuerzas que se producen en los arranques, que previamente eran puramente de tracción, ahora son de compresión. Obtenemos, por tanto, un arco comprimido que deberá estar dotado de una sustentación que resista empujes, o bien tenga un tirante traccionado. 
En el caso de la construcción de arcos de forma no antifunicular, existen dos opciones óptimas:

1. Dotar al arco de un grueso suficiente como para que el antifunicular pase por los márgenes de variación previstos.

2. Dotar al arco de rigidez a flexión, descartando el uso de piedra o ladrillo, dejando paso al hormigón armado o al acero.
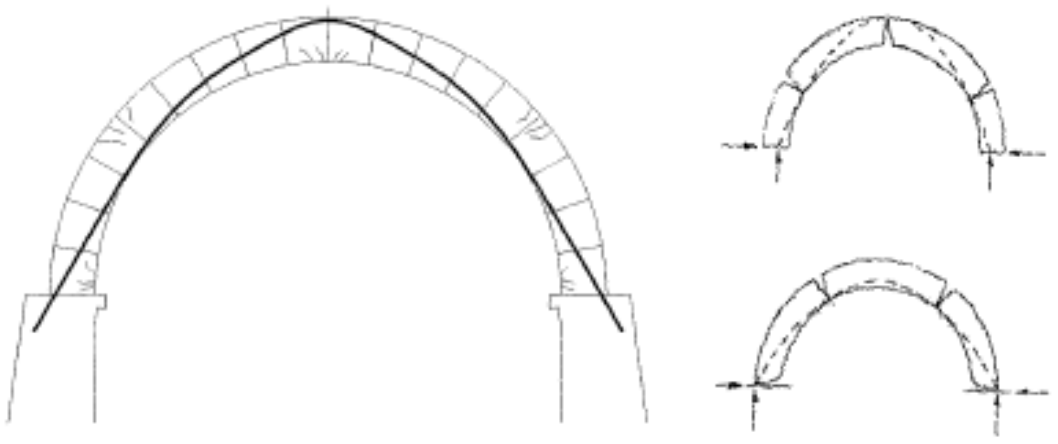

Fig. 16: Arco dentro de los límites del antifunicular.

Fig. 17: Posiciones extremas de las líneas de empujes.

Los empujes horizontales pueden resolverse con tirantes, como en el caso de la arquitectura renacentista, o mediante masas que hagan vertical la resultante, siendo el caso del gótico o el románico.

La descripción matemática de una catenaria, tomando su mínimo en el punto $(0, \mathrm{~h})$, es:

$$
y=h \cdot \cosh \left(\frac{x}{h}\right)=\frac{h}{2} \cdot\left(e^{x / h}+e^{-x / h}\right)
$$

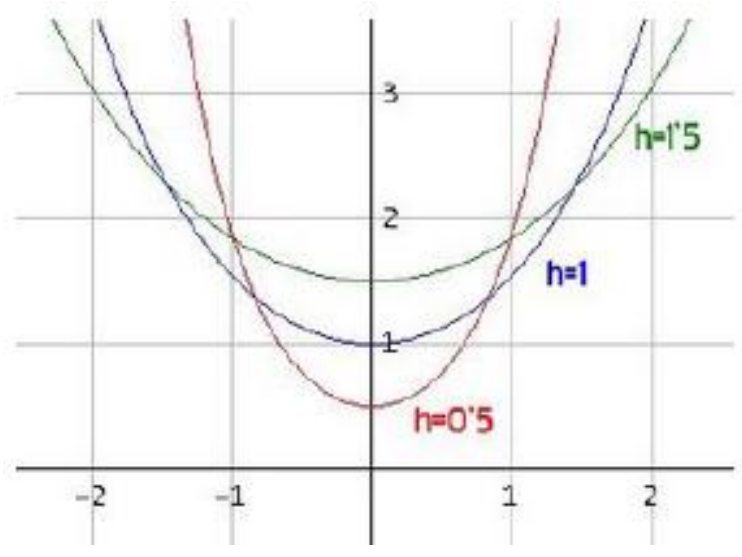

Deducido a partir del siguiente esquema: 


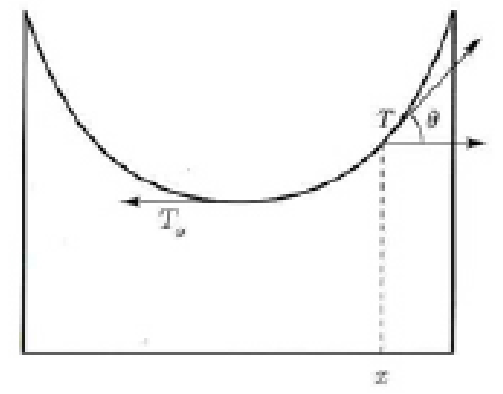

$$
\begin{aligned}
& T \cdot \cos \theta=T_{0}, T \cdot \operatorname{sen} \theta=w \cdot s(x) \\
& \frac{d y}{d x}=\operatorname{tg} \theta=\frac{w \cdot s}{T_{0}} \\
& \frac{d s}{d x}=\sqrt{1+\left(\frac{d y}{d x}\right)^{2}}=\frac{w}{T_{0}} \cdot \frac{d^{2} y}{d x^{2}} \\
& y=a \cosh \left(\frac{x}{a}\right)
\end{aligned}
$$

En el punto mínimo de su gráfica, el valor que alcanza y atiende a la siguiente relación:

$a=\frac{T_{0}}{P}$

Siendo $T_{0}$ la componente horizontal de la tensión, que es constante, y $P$ el peso por unidad de longitud.

Si se desarrolla en series de Taylor la función coseno hiperbólico, $\cosh (x)$, se obtiene que:

$$
\cosh (x)=1+\frac{x^{2}}{2}+O^{4}(x)
$$

Que corresponde a la ecuación de una parábola más un término de cuarto orden, lo que hace que ambas gráficas, la de parábola y la de catenaria, sean tan parecidas en el entorno a cero. La principal diferencia entre ambas curvas corresponde a sus respectivas tangentes, siendo en la catenaria el valor de la tangente tendente a la verticalidad, mientras que en la parábola el valor tiende a una constante. Esto condiciona que en la catenaria, $x$ tiende a valores limitados cuando $y$ tiende a infinito, mientras que en la parábola se obtienen valores infinitos de $x$ cuando $y$ tiende a infinito.

Resumiendo, la catenaria tiene la característica de ser el lugar geométrico de los puntos donde las tensiones horizontales del cable se compensan y, por ello, carecerá de tensiones laterales, por lo que la cadena permanece inmóvil, sin desplazarse hacia los lados. Las fuerzas que actúan son una fuerza vertical, la de la Gravedad, y una tensión tangente a la cadena en cada punto, que es la que la mantiene estirada. Los arcos catenarios transmiten, por tanto, las cargas de presión hacia la cimentación, sin crearse esfuerzos horizontales, salvo en el extremo que llega a los cimientos, por lo que no necesitan apoyos laterales para sustentarse. 


\section{EL PROYECTO ARQUITECTÓNICO}

\subsection{Diseño}

Como punto de partida para el diseño, hay que señalar cuáles serán las claves que configurarán la idea de proyecto, y estas son:

- La estructura deberá trabajar únicamente a compresión, por lo que habrá que hallar las "formas" más simples y puras. El edificio en sí es estructura. Carecerá de ornamentos y huecos innecesarios.

- Se utilizará un único material, siendo éste el hormigón en masa, y sin encofrado alguno.

Por otro lado, de carácter más proyectual, el edificio en planta tendrá forma de cruz latina, a partir de la cual se crearán distintos recorridos por el interior. Conexiones interior-exterior que harán del edificio un elemento de paso para la meditación, la admiración o el encuentro. No se busca un templo cerrado, lleno de imágenes o que simplemente sirva para orar, se pretende crear un espacio para el recuerdo de aquellos por los que se levantó; un espacio para pasear y meditar, como en antiguos cementerios, dónde la naturaleza se mezcla con la arquitectura.

Se busca un icono en medio de un entorno donde el punto de inflexión será tan sólo una leve rampa ascendente, una elevación sobre el terreno a modo de estilóbato, pero haciendo el recorrido continuo.

La entrada de luz se soluciona creando discontinuidades en las partes que conforman cada nave y los accesos carecen de cerramientos, ya que el edificio ha de ser público, logrando un espacio interior luminoso.

Finalmente, el encuentro entre naves que conforman la parte central de la cruz, tomará protagonismo y se elevará, como si quisiera alcanzar el cielo. En esta "cúpula" es donde se producirán entradas de luz solar que cambien con las horas, mostrando el paso del tiempo...

Un templo dónde se podrán realizar ceremonias tanto dentro como fuera, ya que el edifico en sí constituye un altar.

Los siguientes bocetos muestran estas ideas: 
Proyecto arquitectónico basado en la técnica del antifunicular

Laura Butelo Naz

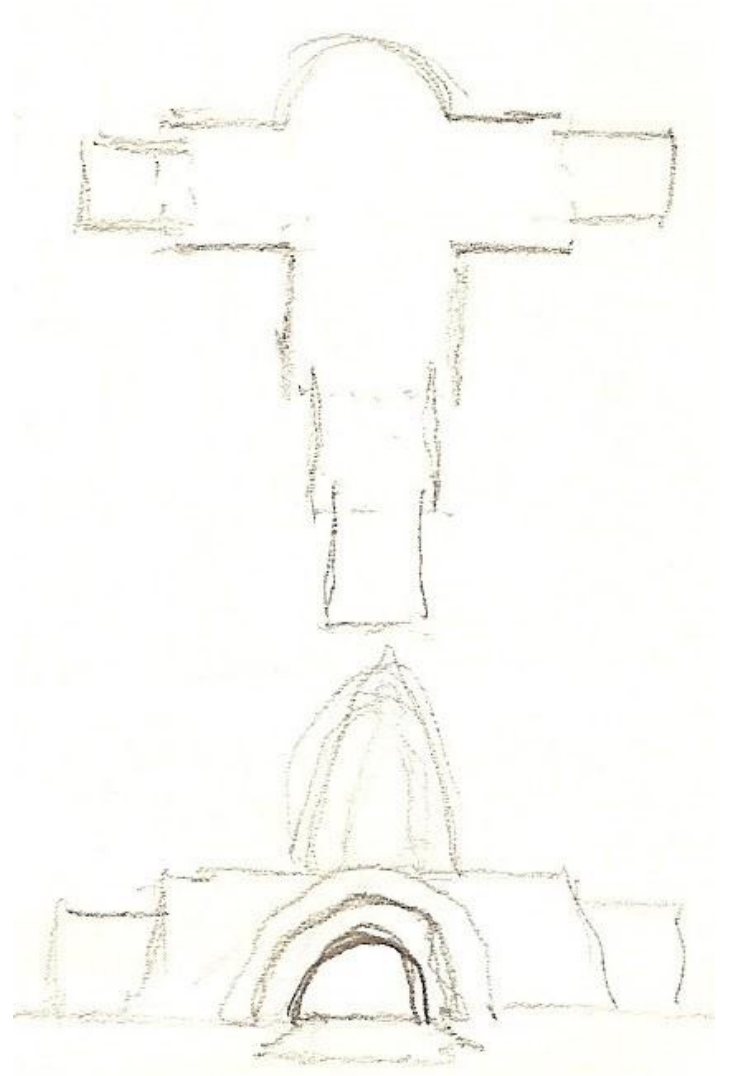

Fig. 18: Planta y alzado principal

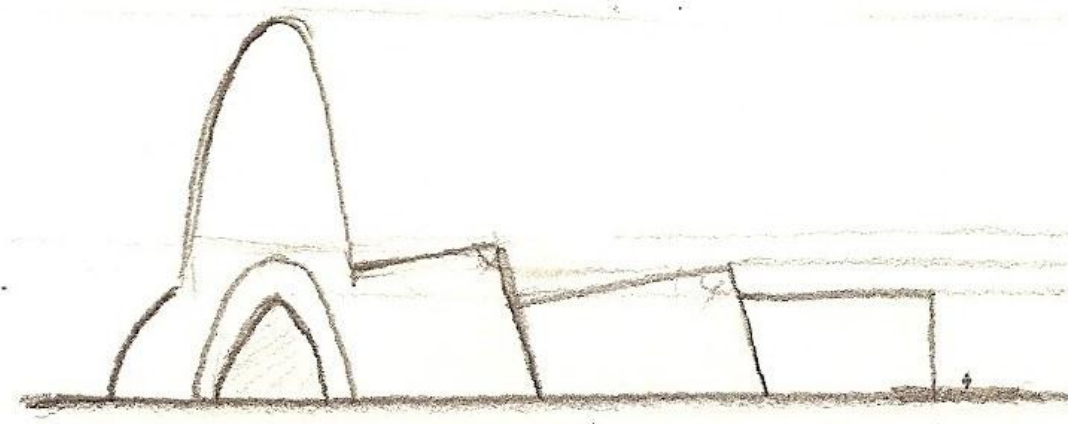

Fig. 19: Alzado lateral

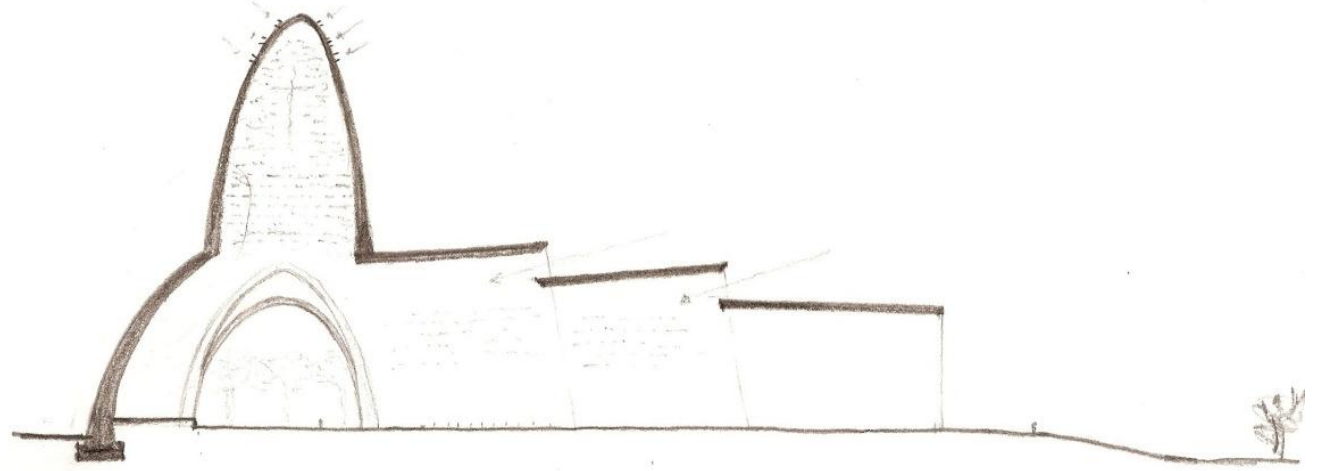

Fig. 20: Sección nave principal

18 


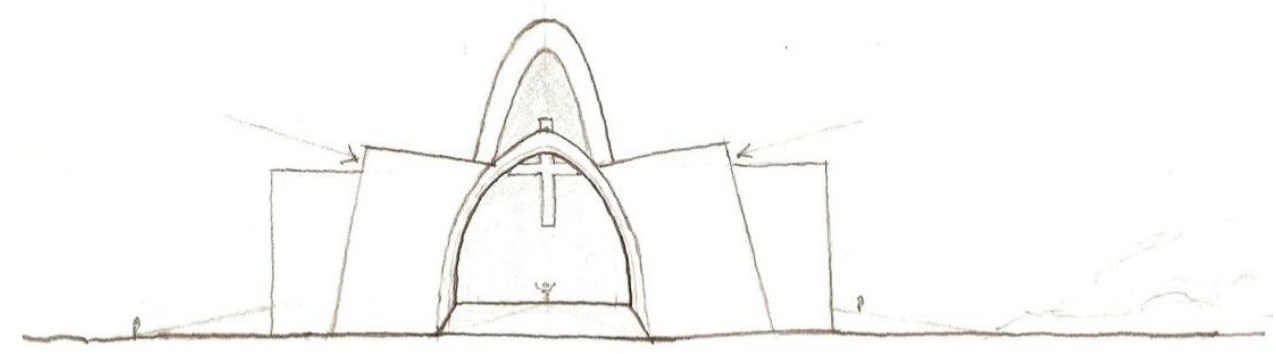

Fig. 21: Alzado principal

La forma estructural vendrá definida por antifuniculares y, para ello, se realizará una maqueta mediante catenarias y se hallarán los esfuerzos, que es el fin de este trabajo. La planta de proyecto, acotada, con la que partiremos será la siguiente:

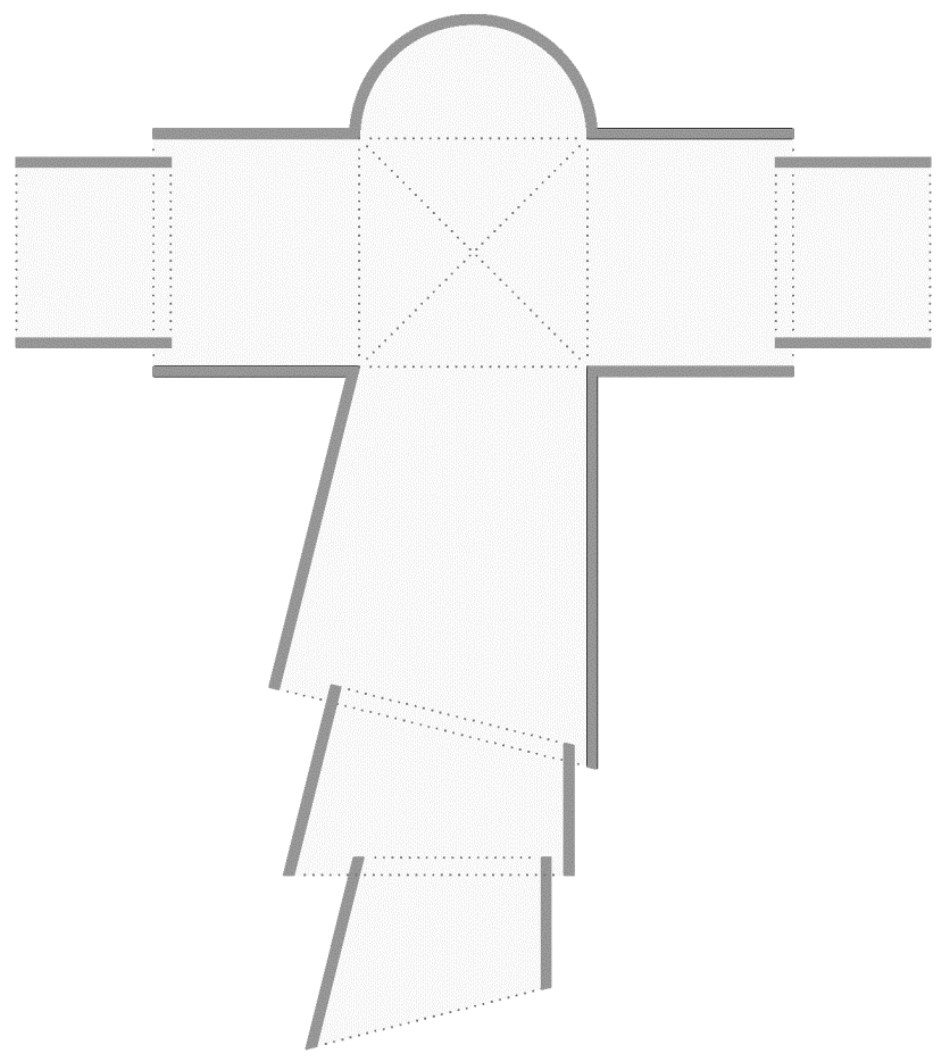

Se adjuntan planos en el anexo 


\section{DESARROLLO}

\subsection{Objetivo}

La finalidad del presente trabajo consiste, pues, en el desarrollo de una maqueta de catenarias para obtener sus antifuniculares. Esta maqueta dará lugar a la forma óptima de la estructura del proyecto, de modo que sólo existan trabajos a compresión, aproximándose al trabajo de Gaudí como medio para realizar los cálculos estructurales de sus obras.

Una vez realizada la maqueta, se digitalizarán las curvas obtenidas y se hallarán sus longitudes y demás parámetros necesarios para obtener las fuerzas resultantes. Un predimensionado alternativo y bastante aproximado al resultado real.

\subsection{Instrumentación y preparación}

Los materiales requeridos son los siguientes:

- Soporte rígido suspendido con espacio necesario para que las cadenas cuelguen sin obstáculos.

- Enganches para colgar las cadenas, que deberán estar fijados al soporte.

- Cadenas de distinto tamaño: eslabones de 15 y $25 \mathrm{~mm}$.

- Cámara fotográfica para recoger las curvas proporcionadas por las cadenas (catenarias) y poder ser digitalizadas posteriormente.

- Instrumentos de medición.

Una vez fijado el soporte y los enganches, se colocarán cadenas en función de la planta de proyecto, situando al menos dos cadenas en cada extremo de cada parte de las naves. La altura se aproximará a la prevista en los bocetos, pero la altura final de proyecto vendrá dada por las distintas catenarias una vez colocadas en su totalidad.

La parte más compleja es la del encuentro central, entre las naves, que consta de una especie de cúpula. Dicha cúpula estará constituida por cuatro nervios que arrancan desde los encuentros de las naves. De nervio a nervio, a su vez, partirán varias catenarias. Estas catenarias secundarias estarán formadas por cadenas de menor densidad, intentando acercarse más a la realidad. El resto de las catenarias estarán constituidas por las cadenas más densas. Aunque esto no tendrá especial relevancia en el resultado final, aunque sí en la forma que adoptarán los nervios de la cúpula, ya que si colocásemos cadenas más densas, éstas provocarían una deformación mayor (se comparará en el apartado siguiente). 


\subsection{Toma de muestras}

Una vez completada la maqueta, se procederá a la toma de muestras, es decir, a fotografiar con la menor perspectiva posible cada una de las catenarias. Posteriormente, mediante un programa de dibujo digital (Autocad) se escalarán las imágenes y se dibujarán las curvas formadas por cada cadena suspendida. Se escalarán de acuerdo a medidas tomadas en la maqueta, éstas son la altura de catenaria (desde el soporte hasta la tangente horizontal de la catenaria) y la verificación de la distancia entre arranques, ya que éstos se habían especificado previamente. Las curvas se crearán mediante polilínea spline, que mediante el comando list obtendremos sus propiedades.

De cada catenaria tenemos por tanto, su altura $h$, la distancia entre arranques $a$ y su longitud $L$, hallada una vez dibujada digitalmente. Como espesor de partida para las piezas de hormigón en masa, se ha tomado 0,80 metros en los arranques, que irá disminuyendo en altura ascendente.

Cada una de las catenarias se clasifica en función de su posición en planta y de su orden, de exterior a interior, en cada elemento que forman las naves.

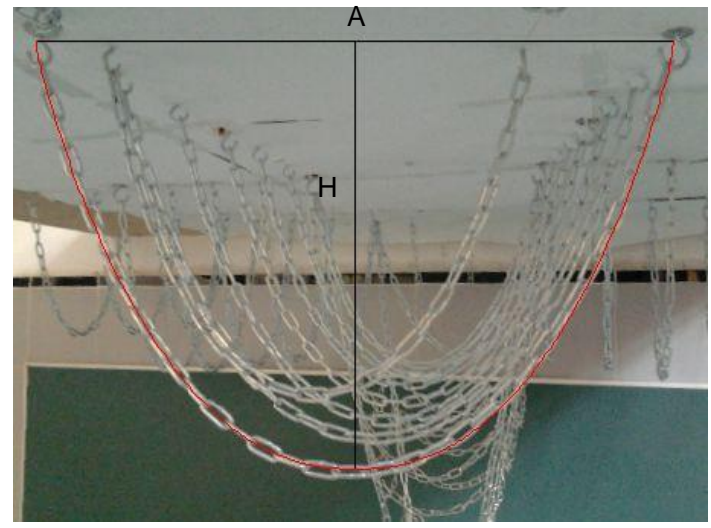

Fig. 22: Digitalización de curvas

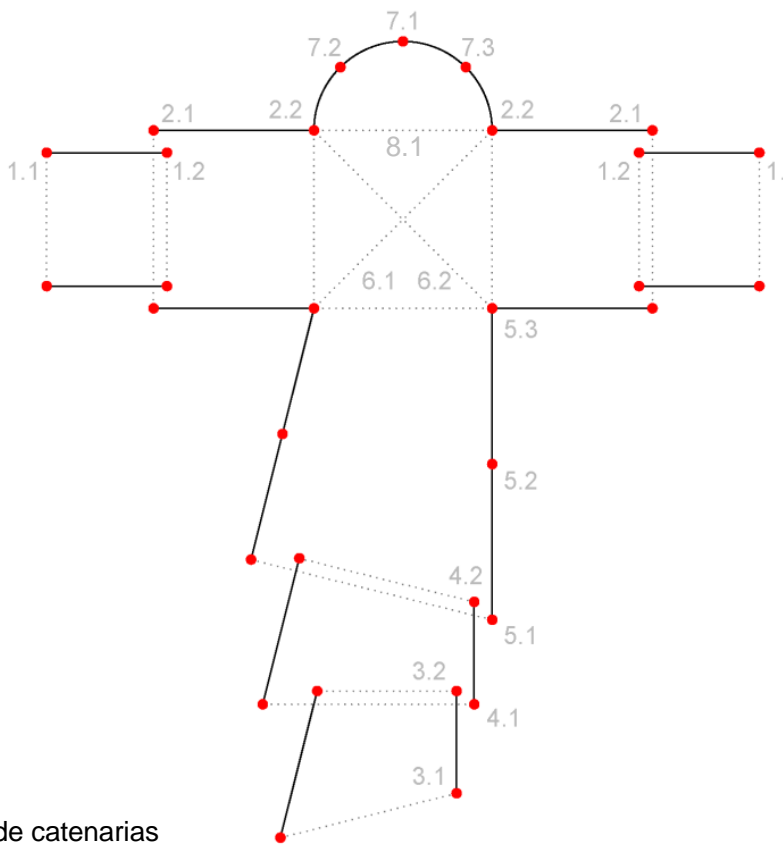

Fig. 23: Posición arranques de catenarias

\subsection{Cálculo de fuerzas}

Para hallar las fuerzas distribuidas a lo largo de cada arco catenario, se dividirá éste en varias partes, cada 5 metros, desde el arranque, de modo que obtengamos las fuerzas para cada espesor a lo largo de la curva. Se obtendrá, para cada corte, el ángulo tangencial que forma la 
curva con la horizontal en cada punto. Mediante la fuerza resultante y el ángulo obtendremos las componentes horizontales y verticales.

La fuerza se hallará en función de la densidad del hormigón que recae sobre cada punto de corte:

$$
F=\gamma \cdot L \cdot e \cdot d
$$

Siendo:

$\boldsymbol{\gamma}=$ Fuerza ejercida por el hormigón en masa, que tomaremos como $25 \mathrm{kN} / \mathrm{m}^{3}$, tomando la fuerza de la gravedad como $10 \mathrm{kN}$, y su densidad como 2.500 $\mathrm{Kg} / \mathrm{m}^{3}$ (la densidad del hormigón en masa oscila entre 2.300 y $2.500 \mathrm{Kg} / \mathrm{m}^{3}$ )

$\mathbf{L}=$ longitud de arco que recae sobre el punto de corte $(\mathrm{m})$

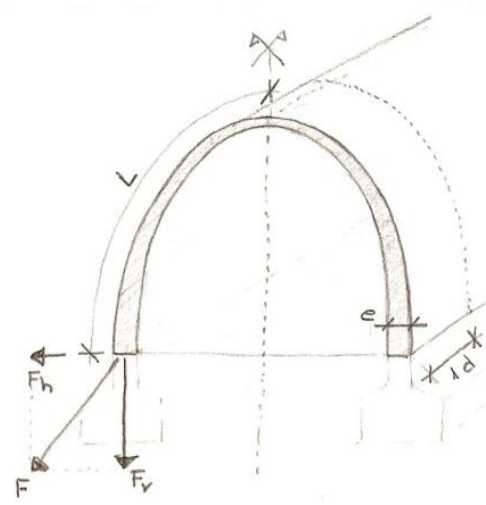

$\mathbf{e}=$ espesor del arco en ese punto. Tomará valores desde 0,40 $\mathrm{m}$ hasta 1,10 m

$\mathbf{d}=$ distancia longitudinal horizontal. Tomaremos el valor unidad, $1 \mathrm{~m}$

Si tomamos $F / d$ obtendremos la densidad de fuerza por unidad de longitud.

$$
F / d(\mathrm{kN} / \mathrm{m})=\gamma \cdot L \cdot e
$$
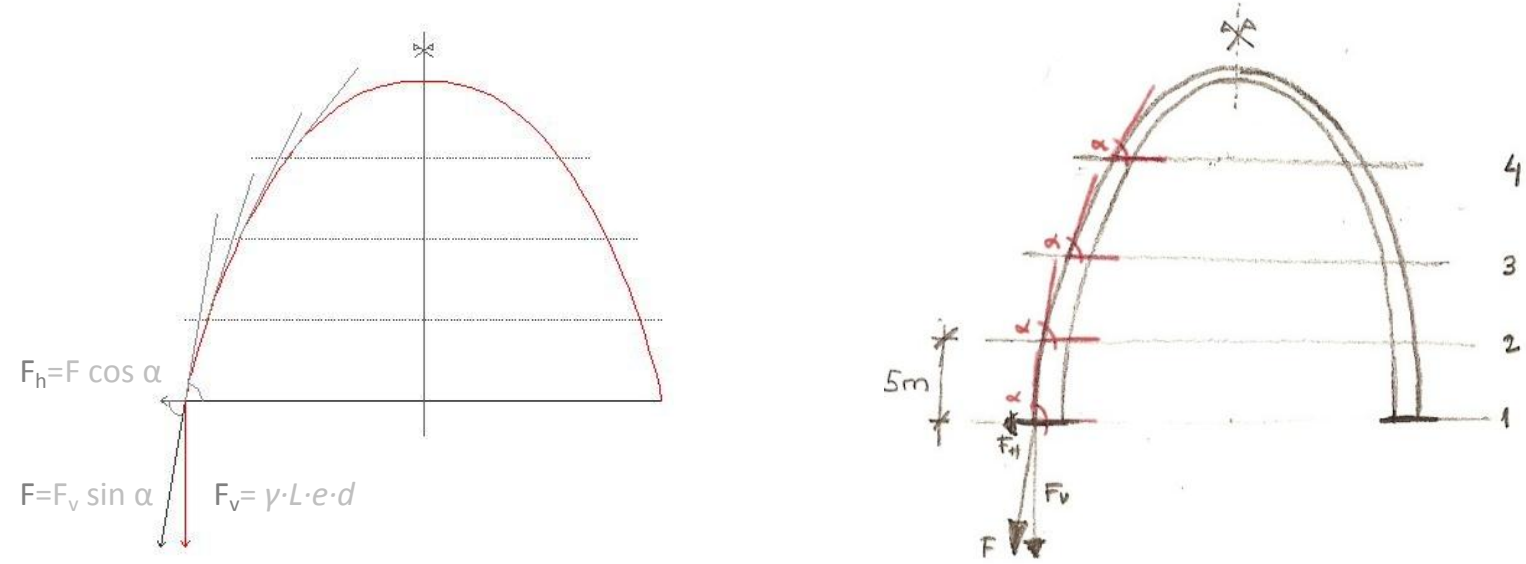

La fuerza $F_{v}$ es la producida por el peso específico del hormigón, por lo que, a partir del ángulo $\alpha$ que forma con la horizontal, obtendremos la fuerza real $\mathrm{F}$ a lo largo de la curva.

A continuación se muestran los resultados de cada parte del proyecto, mostrándose en negrita la fuerza resultante en cada arranque (sólo a un lado de la simetría): 
Nave lateral (catenarias 1.1, 1.2, 2.1, 2.2)

\begin{tabular}{|c|c|c|c|c|c|c|c|}
\hline Catenaria & Corte & $\begin{array}{l}\text { Longitud } \\
\text { L (m) }\end{array}$ & $\begin{array}{c}\text { Espesor } \\
\text { e (m) }\end{array}$ & $\begin{array}{c}\text { Ángulo } \\
\qquad \alpha\end{array}$ & $\begin{array}{l}\text { Fuerza } F_{v} \\
(\mathrm{kN} / \mathrm{m})\end{array}$ & $\begin{array}{l}\text { Componente } \\
\text { horizontal } F_{\mathrm{h}} \\
(\mathrm{kN} / \mathrm{m})\end{array}$ & $\begin{array}{c}\text { Resultante F } \\
(\mathrm{kN} / \mathrm{m})\end{array}$ \\
\hline Nave & 1 & 18.47 & 0.60 & $85^{\circ}$ & 277.05 & 24.239 & 278.11 \\
\hline lateral & 2 & 13.4 & 0.50 & $76^{\circ}$ & 167.5 & 41.762 & 172.628 \\
\hline $\begin{array}{c}1.1 \\
H=15.13 \mathrm{~m} \\
A=16 \mathrm{~m}\end{array}$ & 3 & 8.08 & 0.40 & $64^{\circ}$ & 80.8 & 39.41 & 89.90 \\
\hline 1.2 & 1 & 17.04 & 0.60 & $82^{\circ}$ & 255.6 & 35.922 & 258.112 \\
\hline $\mathrm{H}=13.6 \mathrm{~m}$ & 2 & 11.92 & 0.50 & $73^{\circ}$ & 149 & 45.554 & 155.808 \\
\hline$A=16 m$ & 3 & 6.55 & 0.40 & $59^{\circ}$ & 65.5 & 39.356 & 76.414 \\
\hline Nave & 1 & 22.63 & 0.80 & $78^{\circ}$ & 452.6 & 95.862 & 461.071 \\
\hline lateral & 2 & 17.52 & 0.60 & $75^{\circ}$ & 262.87 & 70.436 & 272.143 \\
\hline $\begin{array}{c}2.1 \\
H=19 m\end{array}$ & 3 & 12.29 & 0.50 & $70^{\circ}$ & 153.7 & 55.942 & 163.564 \\
\hline$A=20 m$ & 4 & 6.72 & 0.40 & $55^{\circ}$ & 67.5 & 47.264 & 82.402 \\
\hline 2.2 & 1 & 21.22 & 0.80 & $81^{\circ}$ & 424.4 & 67.218 & 429.69 \\
\hline $\mathrm{H}=17.1 \mathrm{~m}$ & 2 & 16.12 & 0.60 & $74^{\circ}$ & 241.8 & 69.335 & 251.544 \\
\hline$A=20 m$ & 3 & 10.82 & 0.50 & $68^{\circ}$ & 135.25 & 54.644 & 145.872 \\
\hline & 4 & 4.98 & 0.40 & $43^{\circ}$ & 49.8 & 53.404 & 73.021 \\
\hline
\end{tabular}

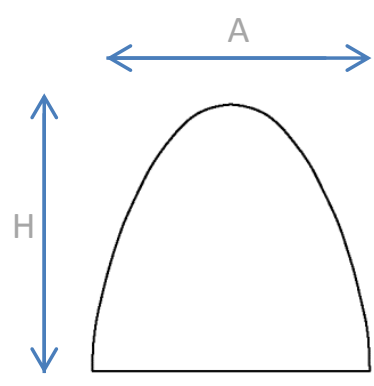

Nave lateral. Cat 1.1

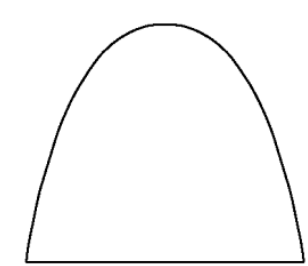

Nave lateral. Cat 1.2

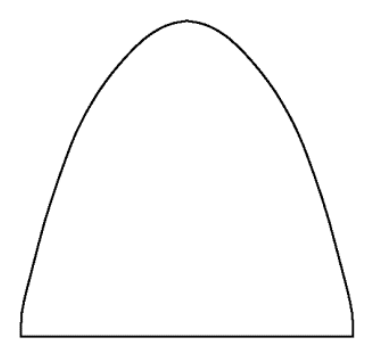

Nave lateral. Cat 2.1

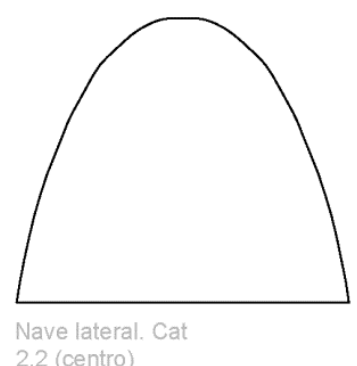

2.2 (centro) 
Nave principal (catenarias 3.1, 3.2, 4.1, 4.2, 5.1, 5.2, 5.3)

\begin{tabular}{|c|c|c|c|c|c|c|c|}
\hline Catenaria & Corte & $\begin{array}{l}\text { Longitud } \\
\text { L (m) }\end{array}$ & $\begin{array}{c}\text { Espesor } \\
\text { e (m) }\end{array}$ & $\begin{array}{c}\text { Ángulo } \\
\alpha\end{array}$ & $\begin{array}{c}\text { Fuerza } F_{v} \\
(\mathrm{kN} / \mathrm{m})\end{array}$ & $\begin{array}{l}\text { Componente } \\
\text { horizontal } F_{h} \\
\qquad(k N / m)\end{array}$ & $\begin{array}{c}\text { Resultante F } \\
\text { (kN/m) }\end{array}$ \\
\hline \multirow{3}{*}{$\begin{array}{c}\text { Nave } \\
\text { principal } \\
3.1 \\
\begin{array}{c}\mathrm{H}=14.67 \mathrm{~m} \\
\mathrm{~A}=20 \mathrm{~m}\end{array}\end{array}$} & 1 & 18.61 & 0.60 & $76^{\circ}$ & 279.15 & 69.60 & 287.696 \\
\hline & 2 & 13.33 & 0.50 & $70^{\circ}$ & 166.625 & 60.646 & 177.319 \\
\hline & 3 & 7.69 & 0.40 & $57^{\circ}$ & 76.9 & 49.94 & 91.693 \\
\hline \multirow{3}{*}{$\begin{array}{c}3.2 \\
H=14.67 \mathrm{~m} \\
A=15.6 \mathrm{~m}\end{array}$} & 1 & 16.47 & 0.60 & $85^{\circ}$ & 247.05 & 21.614 & 247.994 \\
\hline & 2 & 11.3 & 0.50 & $72^{\circ}$ & 141.25 & 45.895 & 148.519 \\
\hline & 3 & 5.81 & 0.40 & $59^{\circ}$ & 58.1 & 34.91 & 67.781 \\
\hline \multirow{2}{*}{$\begin{array}{c}\text { Nave } \\
\text { principal }\end{array}$} & 1 & 22.17 & 0.80 & $79^{\circ}$ & 443.4 & 86.188 & 451.699 \\
\hline & 2 & 16.93 & 0.60 & $70^{\circ}$ & 253.95 & 92.43 & 270.248 \\
\hline \multirow{2}{*}{$\begin{array}{c}4.1 \\
H=17.34 \mathrm{~m} \\
A=23.67 \mathrm{~m}\end{array}$} & 3 & 11.49 & 0.50 & $60^{\circ}$ & 143.625 & 82.922 & 165.844 \\
\hline & 4 & 5.4 & 0.40 & $40^{\circ}$ & 54 & 64.355 & 84.01 \\
\hline \multirow{4}{*}{$\begin{array}{c}4.2 \\
H=17.1 \mathrm{~m} \\
A=20 \mathrm{~m}\end{array}$} & 1 & 21.07 & 0.80 & $85^{\circ}$ & 421.4 & 36.868 & 423.01 \\
\hline & 2 & 15.97 & 0.60 & $75^{\circ}$ & 239.55 & 64.187 & 248.00 \\
\hline & 3 & 10.63 & 0.50 & $68^{\circ}$ & 132.875 & 53.685 & 143.31 \\
\hline & 4 & 4.73 & 0.40 & $43^{\circ}$ & 47.3 & 50.723 & 69.355 \\
\hline \multirow{2}{*}{$\begin{array}{c}\text { Nave } \\
\text { principal }\end{array}$} & 1 & 26.52 & 0.80 & $80^{\circ}$ & 530.4 & 93.524 & 538.582 \\
\hline & 2 & 21.33 & 0.60 & $73^{\circ}$ & 319.95 & 97.818 & 334.569 \\
\hline \multirow{2}{*}{$\begin{array}{c}5.1 \\
H=19.78 \mathrm{~m}\end{array}$} & 3 & 15.94 & 0.50 & $66^{\circ}$ & 199.25 & 88.71 & 218.106 \\
\hline & 4 & 10.13 & 0.40 & $53^{\circ}$ & 101.3 & 76.335 & 126.841 \\
\hline 5.2 & 1 & 22.91 & 0.80 & $81^{\circ}$ & 458.2 & 72.572 & 463.911 \\
\hline \multirow{3}{*}{$\begin{array}{l}H=17.96 \mathrm{~m} \\
A=23.3 \mathrm{~m}\end{array}$} & 2 & 17.76 & 0.60 & $74^{\circ}$ & 266.4 & 76.389 & 277.136 \\
\hline & 3 & 12.45 & 0.50 & $68^{\circ}$ & 155.625 & 62.877 & 167.847 \\
\hline & 4 & 6.59 & 0.40 & $49^{\circ}$ & 65.9 & 57.286 & 87.318 \\
\hline 5.3 & 1 & 21.07 & 0.80 & $85^{\circ}$ & 421.4 & 36.868 & 423.01 \\
\hline$H=17.1 \mathrm{~m}$ & 2 & 15.97 & 0.60 & $75^{\circ}$ & 239.55 & 64.187 & 248.00 \\
\hline
\end{tabular}




\begin{tabular}{|l|l|l|l|l|l|l|l|}
\hline $\mathbf{A}=\mathbf{2 0 m}$ & 3 & 10.63 & 0.50 & $68^{\circ}$ & 132.875 & 53.685 & 143.31 \\
\hline 4 & 4.73 & 0.40 & $43^{\circ}$ & 47.3 & 50.723 & 69.355 \\
\hline
\end{tabular}

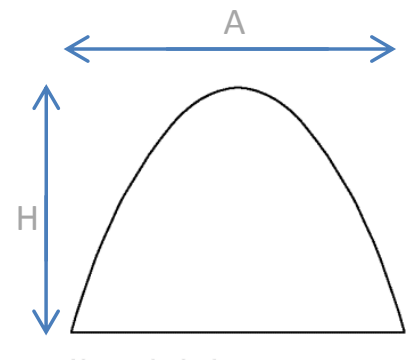

Nave principal. Cat 3.1

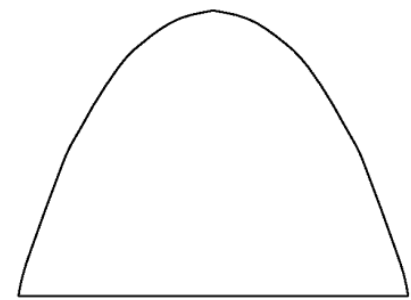

Nave principal. Cat 4.1
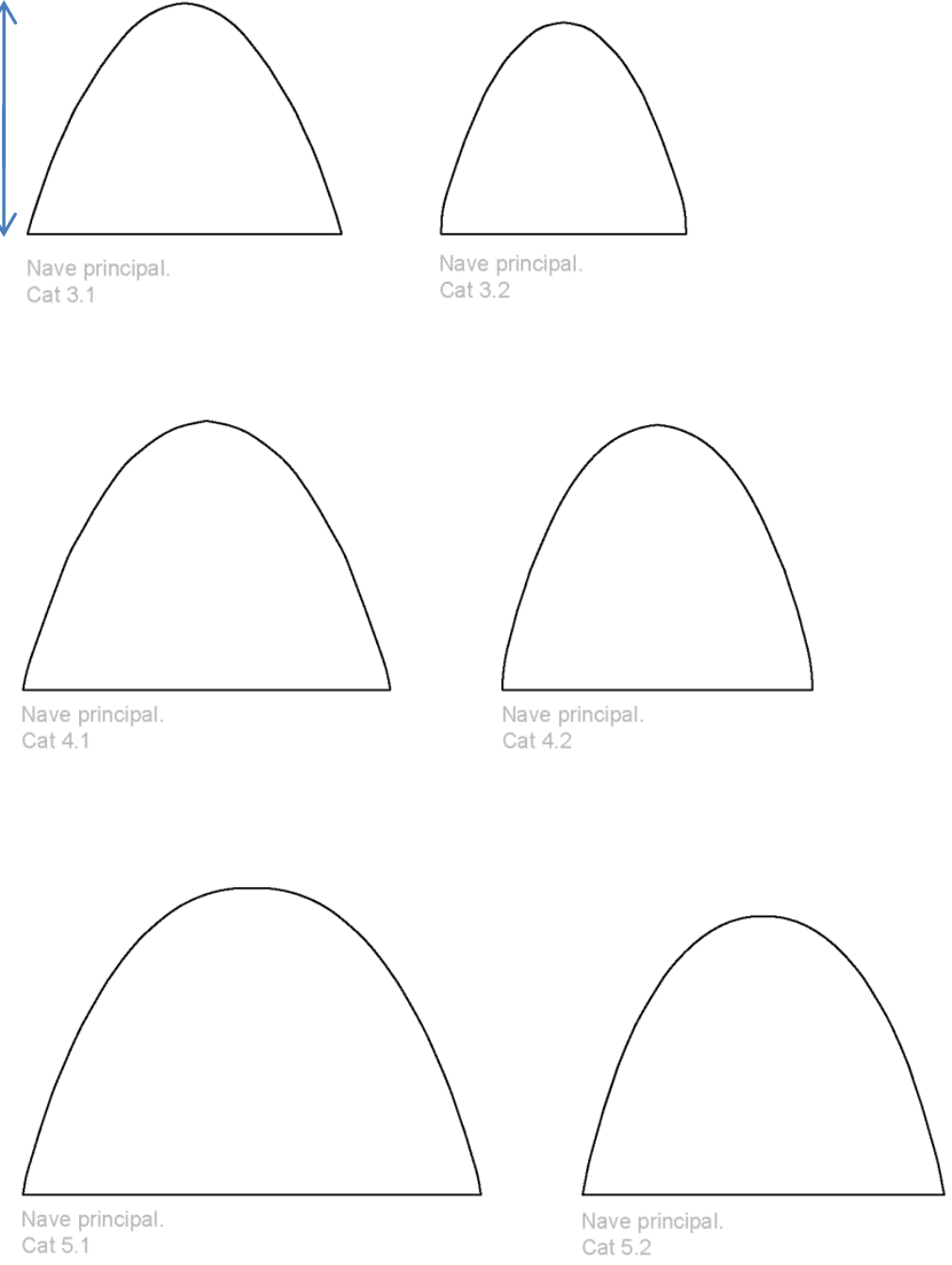

Cúpula (catenarias secundarias apoyadas sobre nervios, S, y nervios, 6.1 y 6.2)

\begin{tabular}{|c|c|c|c|c|c|c|c|}
\hline Cúpula (arcos & 1 & 10.7 & 0.50 & $65^{\circ}$ & 133.75 & 62.371 & 147.582 \\
\hline $\begin{array}{c}S 1 \\
H=6.26 \mathrm{~m} \\
A=15.71 \mathrm{~m}\end{array}$ & & & & & & & \\
\hline
\end{tabular}




\begin{tabular}{|c|c|c|c|c|c|c|c|}
\hline $\begin{array}{c}S 2 \\
H=5.17 \mathrm{~m} \\
A=13.38 \mathrm{~m}\end{array}$ & 1 & 8.95 & 0.50 & $63^{\circ}$ & 111.875 & 57.003 & 125.56 \\
\hline $\begin{array}{c}S 3 \\
H=3.35 \mathrm{~m} \\
A=10.98 \mathrm{~m}\end{array}$ & 1 & 6.72 & 0.50 & $55^{\circ}$ & 84 & 58.817 & 102.545 \\
\hline \multirow[t]{2}{*}{$\begin{array}{c}S 4 \\
H=2.26 \mathrm{~m} \\
A=8.75 \mathrm{~m}\end{array}$} & 1 & 5.13 & 0.50 & $50^{\circ}$ & 64.125 & 53.807 & 83.709 \\
\hline & & & & & 393.75 & 231.998 & \\
\hline $\begin{array}{c}\text { Cúpula } \\
\text { (nervios) } \\
6.1=6.2\end{array}$ & 1 & 43.63 & 1.10 & 77 & $\begin{array}{c}1199.825+ \\
R= \\
1593.575\end{array}$ & $\begin{array}{c}367.906+R=599.9 \\
04\end{array}$ & 1635.492 \\
\hline \multirow[t]{6}{*}{$\begin{array}{c}H=40 m \\
A=28.3 m\end{array}$} & 2 & 38.46 & 1.00 & 76.8 & $961.5+R$ & $\begin{array}{c}317.871+R=549.8 \\
69\end{array}$ & 1392.029 \\
\hline & 3 & 33.31 & 0.90 & 76.7 & $\begin{array}{c}749.475+ \\
R\end{array}$ & $\begin{array}{c}270.247+R=502.2 \\
45\end{array}$ & 1174.733 \\
\hline & 4 & 25.74 & 0.80 & 76.5 & $\begin{array}{c}514.8+ \\
393.75= \\
908.55\end{array}$ & $\begin{array}{c}218.124+231.998 \\
=450.122\end{array}$ & 934.367 \\
\hline & 5 & 20.48 & 0.70 & 75.8 & $\begin{array}{c}358.4+260 \\
=618.4\end{array}$ & $\begin{array}{c}156.479+169.627 \\
=326.106\end{array}$ & 637.89 \\
\hline & 6 & 15.25 & 0.60 & 75.5 & $\begin{array}{c}228.75+ \\
148.125= \\
376.875\end{array}$ & $\begin{array}{c}94.362+112.624= \\
206.986\end{array}$ & 376.875 \\
\hline & 7 & 10.37 & 0.50 & 75 & $\begin{array}{c}129.625+6 \\
4.125= \\
193.75\end{array}$ & $\begin{array}{c}51.915+53.807= \\
105.722\end{array}$ & 200.585 \\
\hline
\end{tabular}



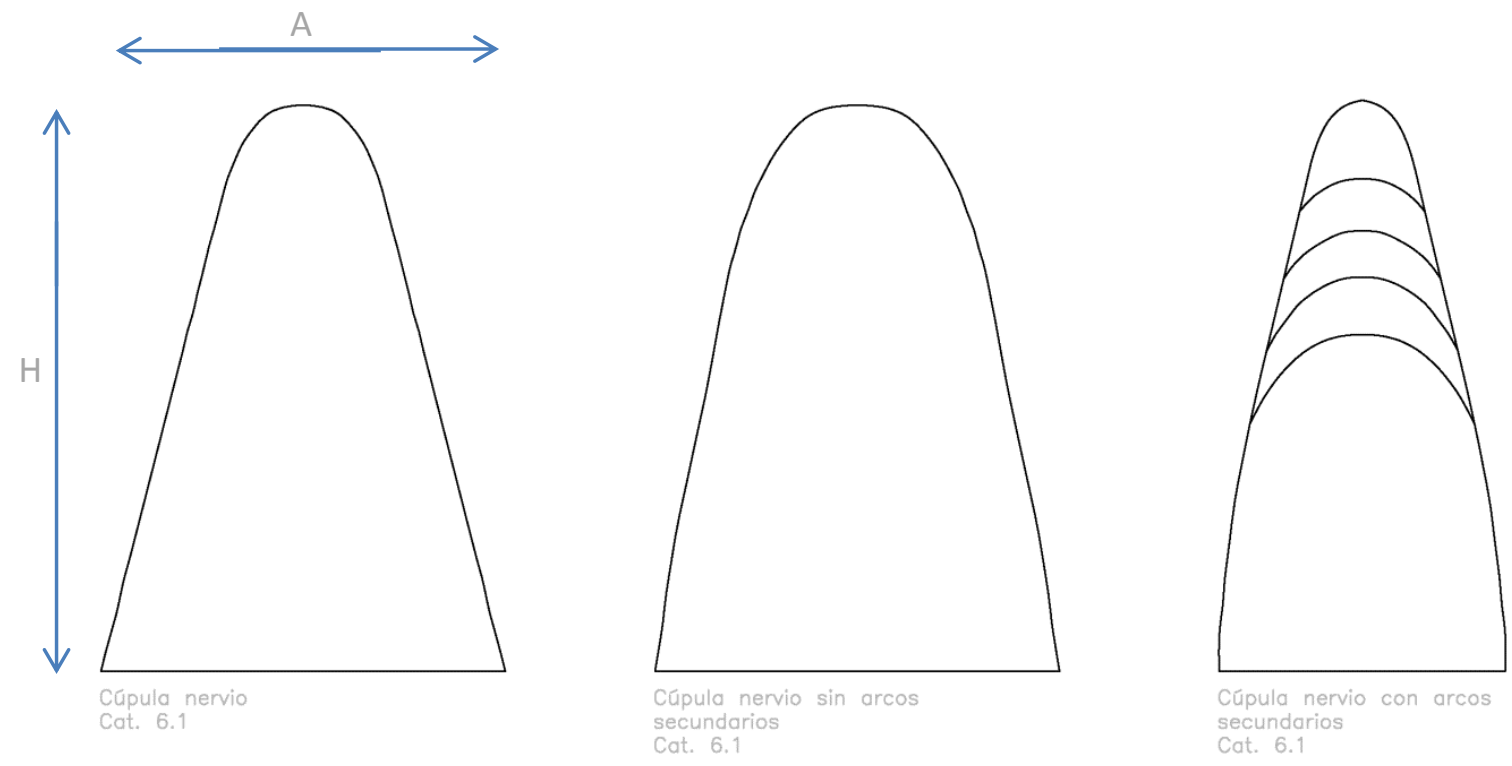

Altar (catenarias 7.1, 7.2, 7.3, 8.1)

\begin{tabular}{|c|c|c|c|c|c|c|c|}
\hline Catenaria & Corte & $\begin{array}{l}\text { Longitud } \\
\text { L (m) }\end{array}$ & $\begin{array}{c}\text { Espesor } \\
\text { e }(\mathrm{m})\end{array}$ & $\begin{array}{l}\text { Ángulo } \\
\qquad \alpha\end{array}$ & $\begin{array}{l}\text { Fuerza } F_{v} \\
(k N / m)\end{array}$ & $\begin{array}{l}\text { Componente } \\
\text { horizontal } F_{\mathrm{h}} \\
(\mathrm{kN} / \mathrm{m})\end{array}$ & $\begin{array}{c}\text { Resultante F } \\
\text { (kN/m) }\end{array}$ \\
\hline \multirow{4}{*}{$\begin{array}{c}7.1=7.2=7.3 \\
H=17.51 \mathrm{~m} \\
A=7.27 \mathrm{~m}\end{array}$} & 1 & 21.18 & 0.80 & $89^{\circ}$ & 423.6 & 7.394 & 423.664 \\
\hline & 2 & 16.17 & 0.60 & $84^{\circ}$ & 242.55 & 25.493 & 243.886 \\
\hline & 3 & 11.1 & 0.50 & $79^{\circ}$ & 138.75 & 26.97 & 141.347 \\
\hline & 4 & 5.85 & 0.40 & $64^{\circ}$ & 58.5 & 28.532 & 65.087 \\
\hline \multirow{2}{*}{$\begin{array}{c}\text { Altar } \\
8.1\end{array}$} & 1 & 21.07 & 0.80 & $85^{\circ}$ & 421.4 & 36.868 & 423.01 \\
\hline & 2 & 15.97 & 0.60 & $75^{\circ}$ & 239.55 & 64.187 & 248.00 \\
\hline \multirow{2}{*}{$\begin{array}{c}H=17.1 \mathrm{~m} \\
A=20 \mathrm{~m}\end{array}$} & 3 & 10.63 & 0.50 & $68^{\circ}$ & 132.875 & 53.685 & 143.31 \\
\hline & 4 & 4.73 & 0.40 & $43^{\circ}$ & 47.3 & 50.723 & 69.355 \\
\hline
\end{tabular}
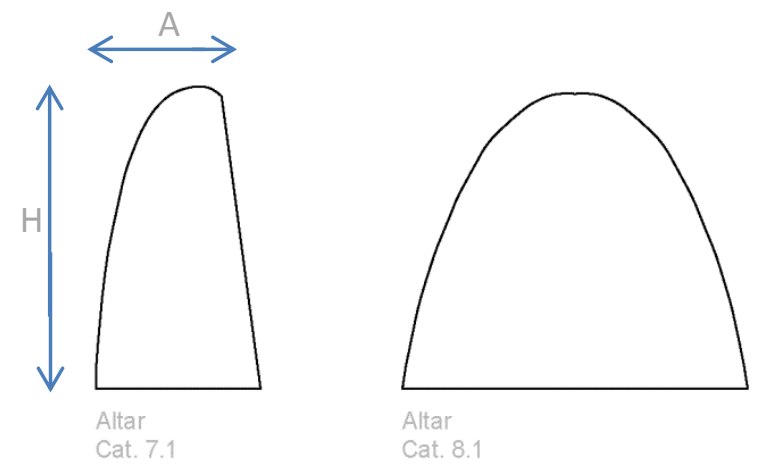


\subsection{Resultados}

El proyecto queda, como resultado, de la siguiente forma:
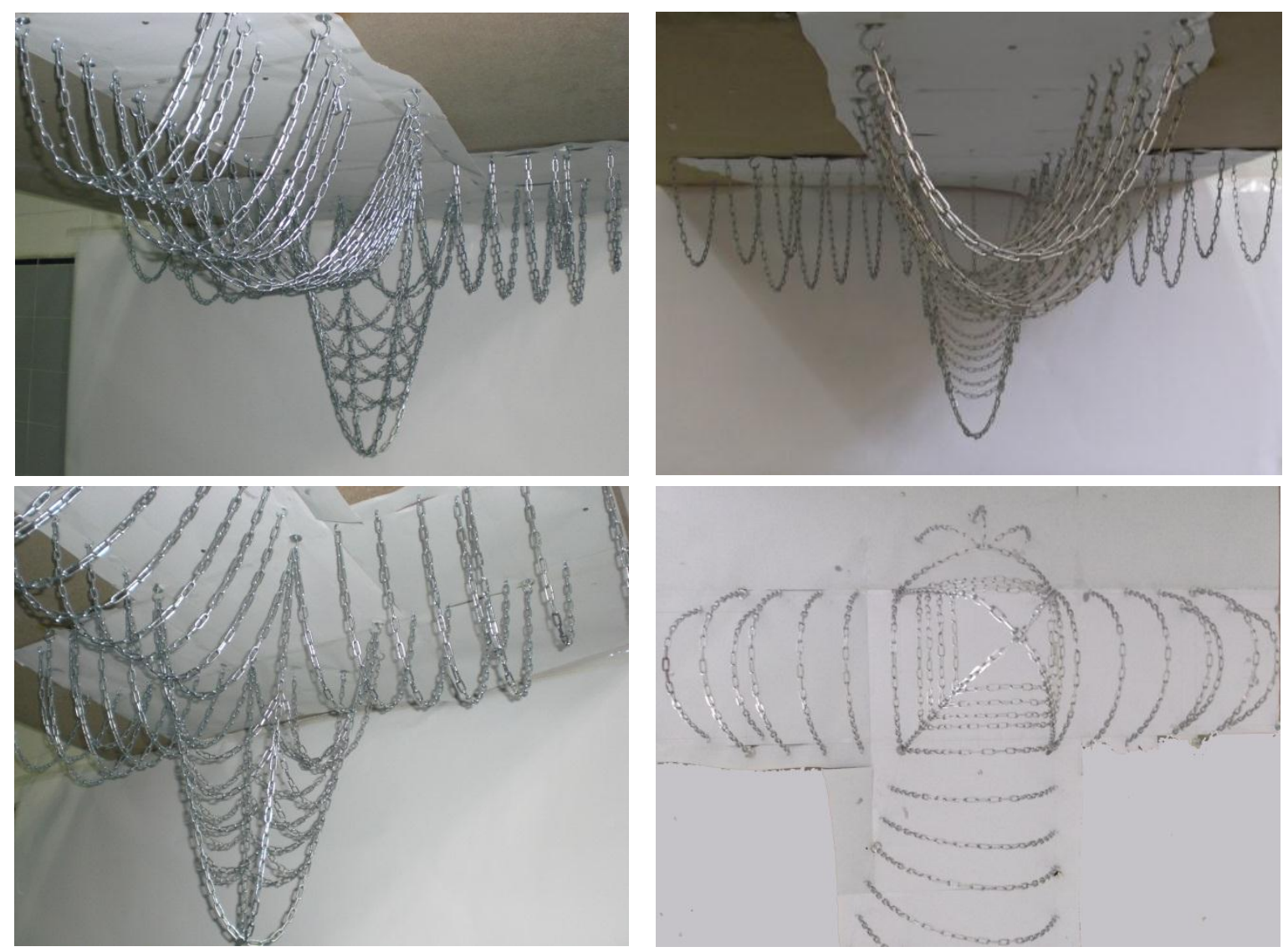

Traspasamos estos resultados a los planos de proyecto:

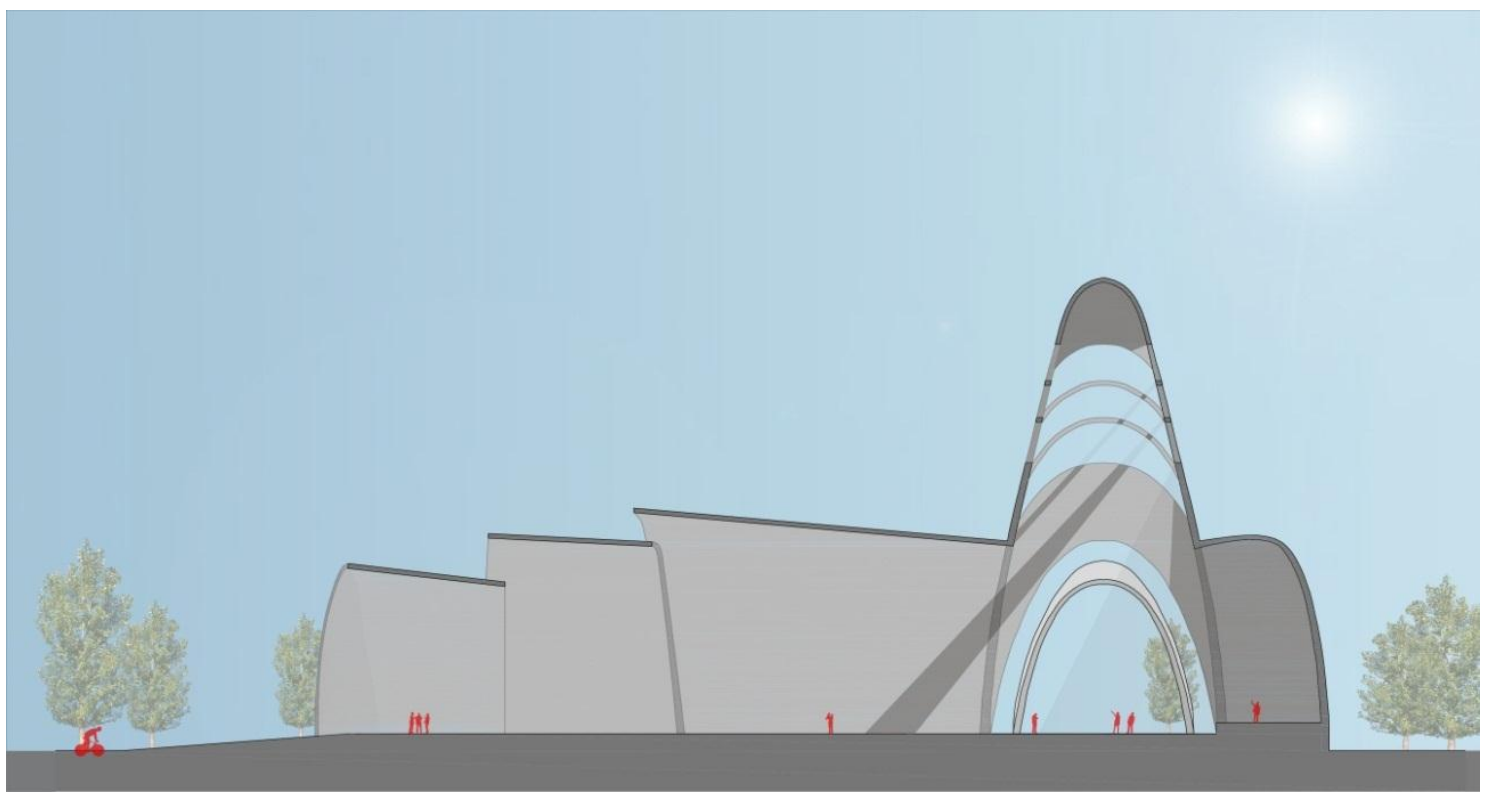

Sección longitudinal 


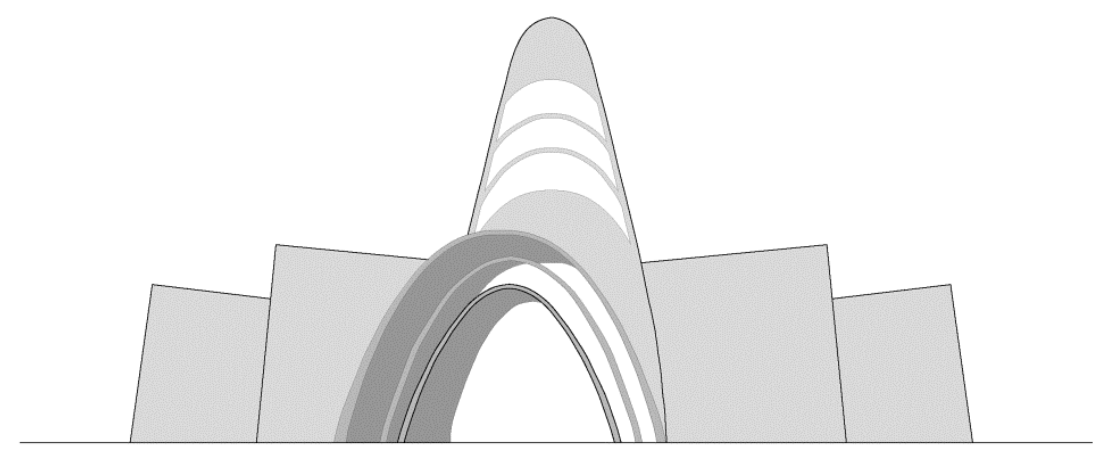

Alzado frontal

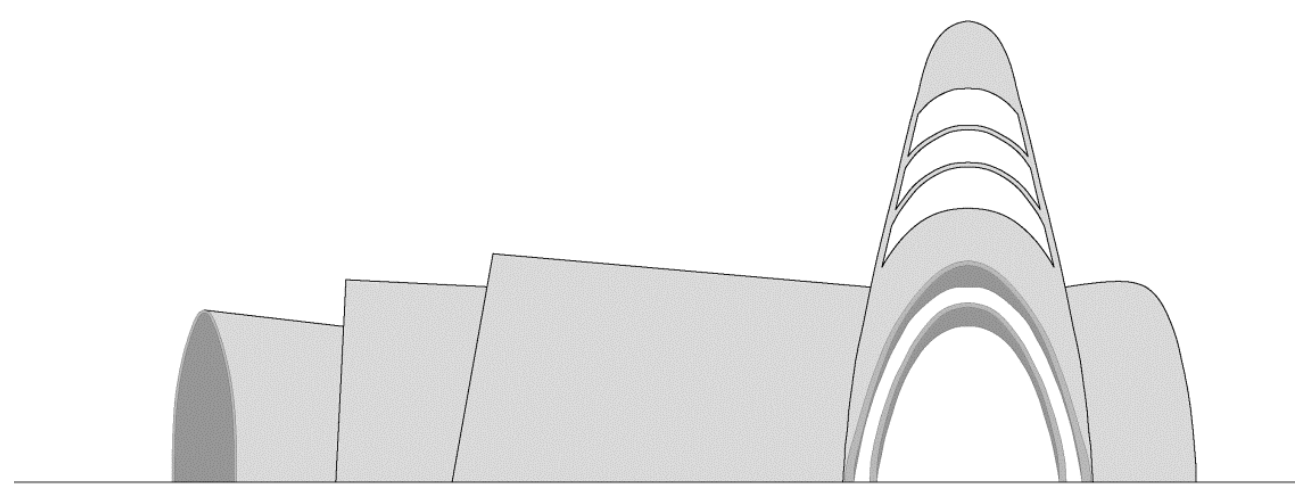

Alzado lateral

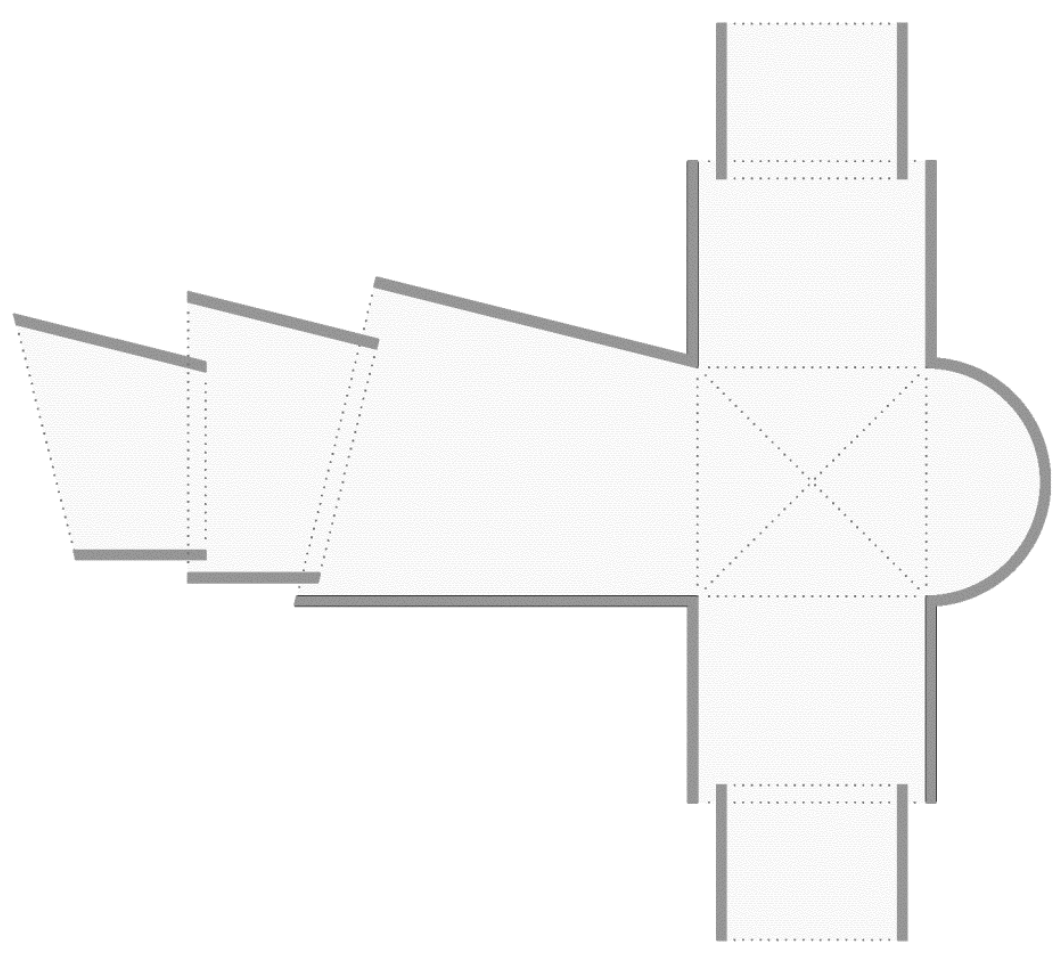


Como aporte y proceso final, se han adherido los eslabones de cada catenaria, de manera que pueda darse la vuelta al soporte y poder tener la maqueta como punto de referencia en el proceso constructivo. Se trata de un adhesivo bifásico de carácter industrial, incoloro y fácil de aplicar, obteniéndose resultados satisfactorios.
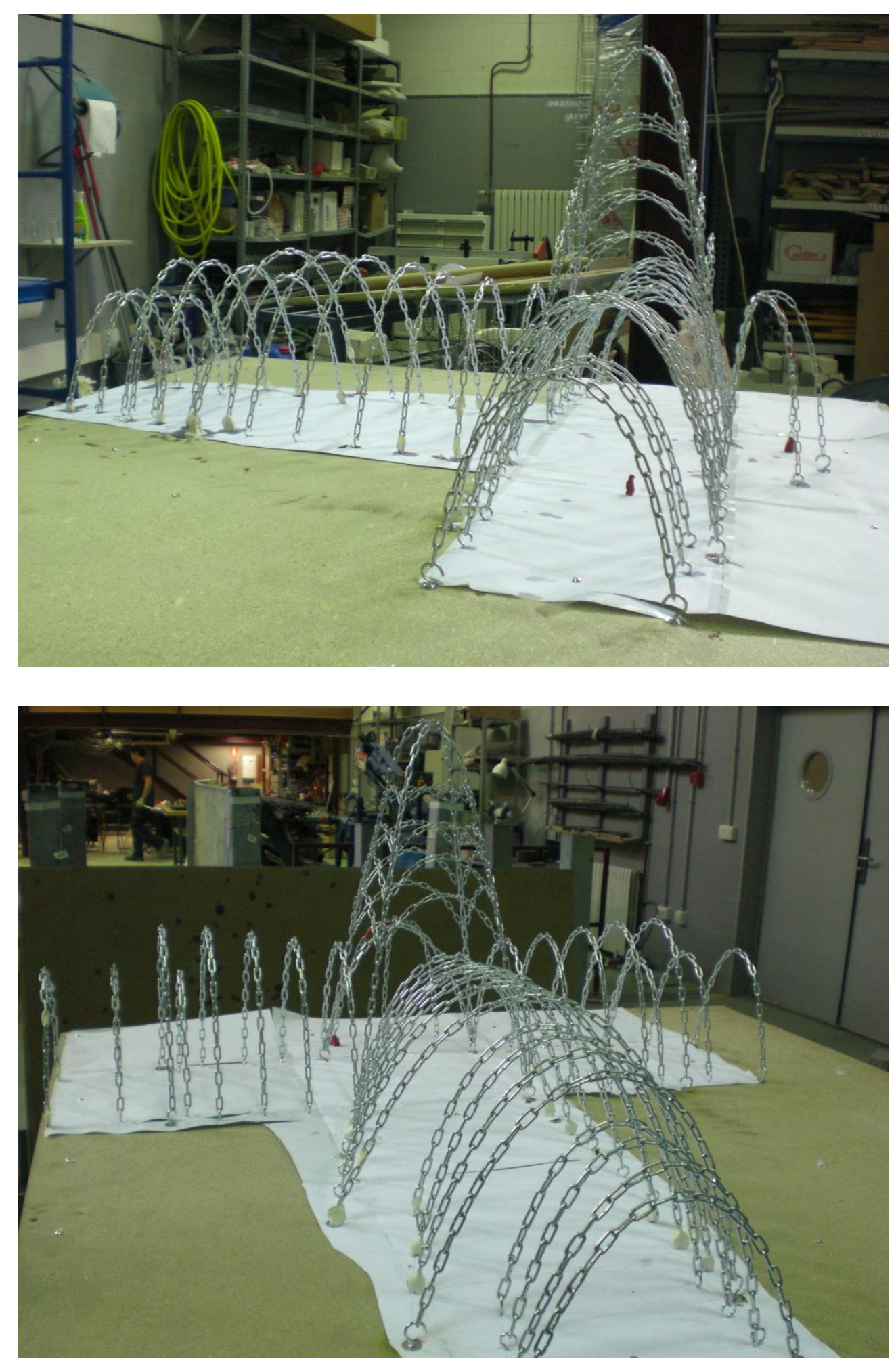


\section{Propuesta de aplicación}

Nos encontramos ante una técnica que no supone un coste elevado, debido al bajo precio de los materiales y a los sencillos cálculos posteriores. A la hora de ejecutarse en obra, el arco catenario requiere menos elementos constructivos y, por tanto, menor inversión económica.

Es una técnica adecuada para desarrollar arquitectura sostenible, por lo anteriormente mencionado. Podrían estudiarse proyectos viables que combinen estructuras catenarias con estudios de aislamiento térmico o refrigeración de espacios, impactos sobre el terreno o incluso para estructuras de emergencia.

Hoy en día la arquitectura requiere innovación, pero ante todo requiere ser cada vez más sostenible, causando el menor daño al medio ambiente y al entorno en el que se encuentre.

Por otro lado, en la línea de esta investigación, podrían realizarse análisis del proyecto mediante el programa Gaudí 1.0, desarrollado en la Universidad de Granada, de manera que se abran nuevos caminos en el campo de la arquitectura. Este programa trabaja con densidades de fuerzas en mallados topológicos y permite lograr formas perfectas en estructuras complejas, catenarias o estructuras de compresión.

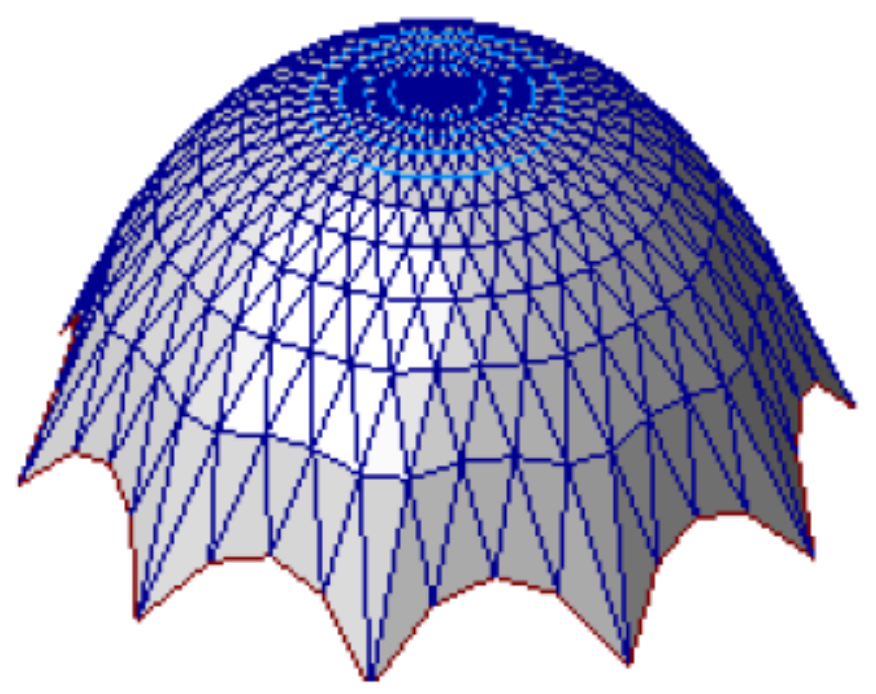

Fig. 24: Ejemplo de estructura mediante Gaudí 1.0 


\section{Conclusiones}

A día de hoy, la arquitectura busca reinventarse y encontrar su lugar en una sociedad cada vez más exigente, no sólo en cuanto al diseño, sino en su coste y en su capacidad de ofrecer mayores prestaciones. Ese coste reside tanto en los materiales y su construcción, como en su fase anterior, que es la de proyecto y cálculo.

El método descrito en este trabajo, busca la optimización desde su principio. Es un método tradicional, pero de total aplicación en la actualidad. Si existe un método sencillo que funciona, ¿por qué dejarlo atrás?

Se combinan técnicas manuales, como es el desarrollo de la maqueta de catenarias, además de técnicas digitales, dónde se encuentran la tradición con la contemporaneidad. Por otro lado, la sencillez de los cálculos permite un predimensionado en el que se tienen en cuenta los únicos esfuerzos que dominan en estas estructuras, que son los de compresión pura.

Además, arquitectura e ingeniería se mantienen ligadas desde las bases de proyecto, lo que evita costes innecesarios a la hora de adaptar un diseño a su estructura.

Los resultados gráficos obtenidos, permiten trasladarlos directamente al proyecto arquitectónico y, a su vez, cambios en el proyecto pueden aplicarse directamente en la maqueta y obtener nuevos resultados. Los cálculos realizados, tienen en cuenta el peso específico del material a tener en cuenta y el espesor que tenga. En este proyecto, se ha tenido en cuenta una disminución de la sección en sentido ascendente con el fin de aligerar la estructura, sin embargo, tal y como se menciona en el presente documento, la sección necesaria puede ser constante siempre y cuando, la curva catenaria estudiada, se encuentre "dentro" de dicho espesor, evitándose esas tensiones indeseadas.

Un método aplicable a distintos elementos, tanto arquitectónicos como de infraestructuras, obteniendo de la propia forma una estructura óptima. 


\section{Anexos}

7.1 Planos de proyecto 


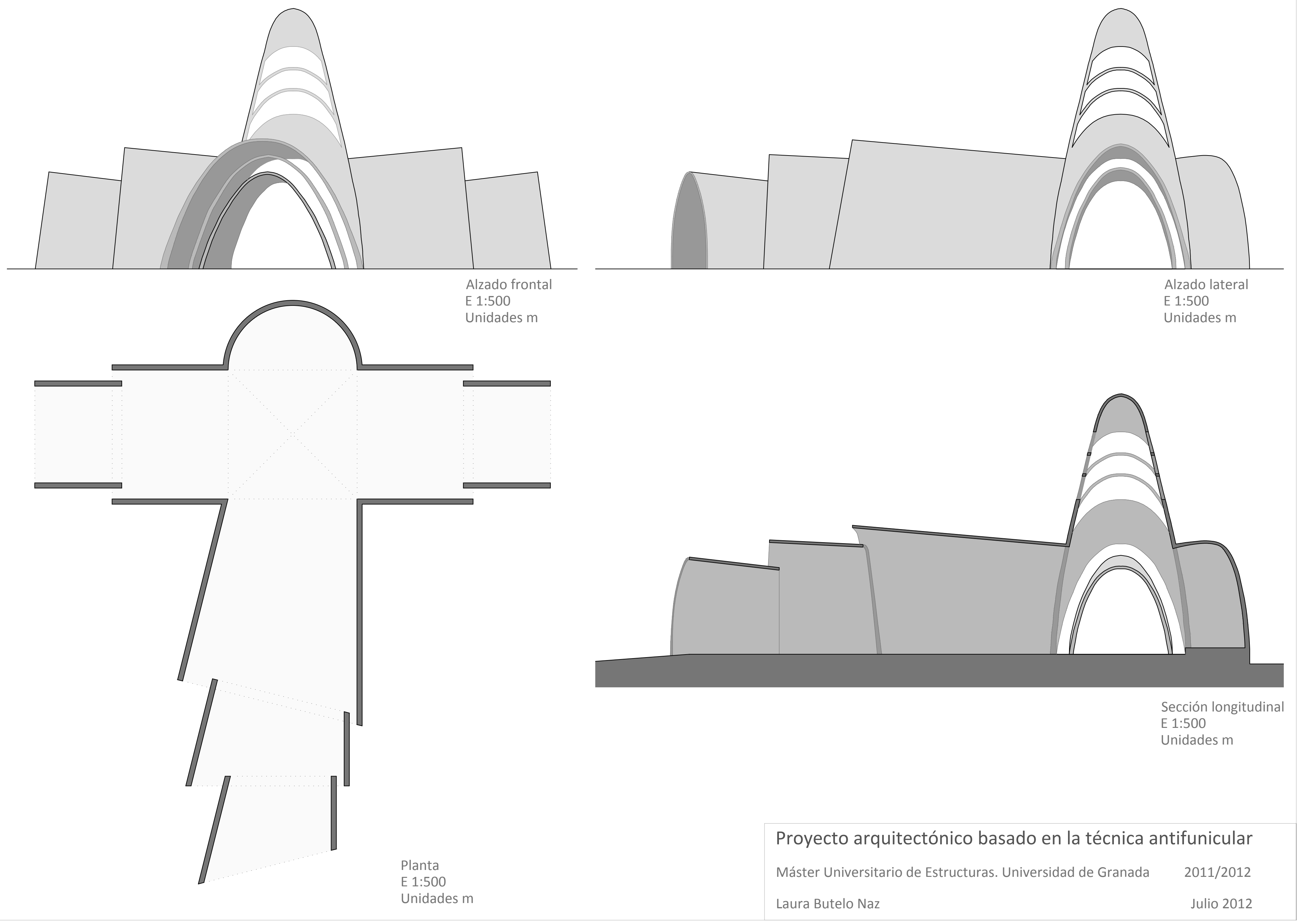



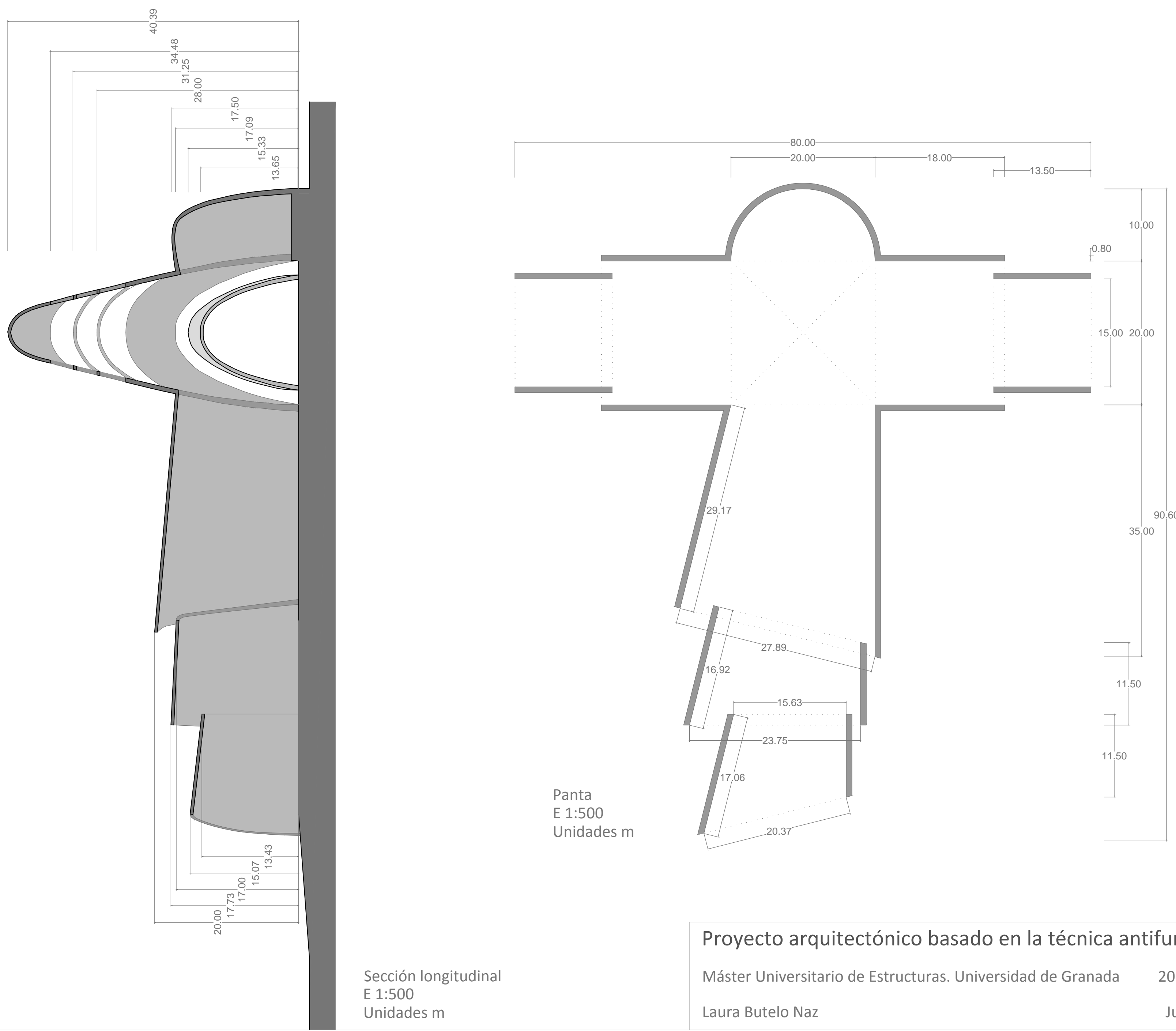

Sección longitudinal 


\section{Referencias}

Ibáñez Torres, R., "El vientro de un arquitecto (La búsqueda de la forma)” En Ibáñez R, Macho M. Ciclo de Conferencias de la Universidad de País Vasco: "Un paseo por la geometría". Curso 2003-04.

Almonacid Cansero, R., "Mies Van der Rohe, es espacio de la ausencia". Ed. Universidad de Valladolid; 90 pags. Valladolid, 2006.

Crippa, MA., "Gaudí. De la Naturaleza a la arquitectura”. Ed Taschen. Colonia 2007. Serraino, P., "Eero Saarinen: Un expresionista estructural”. Ed Taschen. Colonia 2006. Huerta, S., "El cálculo de estructuras en la obra de Gaudí". Ingenieria civil 2003; 129: 121-33.

Dirección General del Patrimonio del Estado, Sociedad estatal para la acción cultural exterior, "Gaudí la busqueda de la forma. Espacio, geometría, estructura y construcción". Barcelona, 2002.

Aroca Hernádez-Ros, R., "Funiculares". Cuadernos del Instituto Juan de Herrera de la Escuela de Arquitectura de Madrid. Cuaderno 52.06. Madrid, 2005.

Hernández Montes, E., Gil Martín, L.M., "Hormigón Armado y Pretensado". Ed. Grupo de Investigación: Ingeniería e Infraestructuras, Universidad de Granada. Granada, 2007.

"EHE. Instrucción de Hormigón Estructural". Secretaría General Técnica. Ministerio de Fomento. Madrid, 1999.

O’Neill, R.C. (Presidente), "Guía para la durabilidad del Hormigón”. ACl 201.2R-01. 2001.

Carbonell Márquez, J.F., Gil Martín, L.M., Hernández Montes, E., Jurado Piña, R., Manual de usuario Gaudí 1.0. Universidad de Granada, 2012. http://hdl.handle.net/10481/20573 